\title{
T cells control the generation of nanomolar-affinity anti-glycan antibodies
}

\author{
Zinaida Polonskaya, ${ }^{1}$ Shenglou Deng, ${ }^{2}$ Anita Sarkar, ${ }^{3}$ Lisa Kain, ${ }^{1}$ Marta Comellas-Aragones, ${ }^{4}$ Craig S. McKay, ${ }^{5}$ \\ Katarzyna Kaczanowska, ${ }^{4}$ Marie Holt, ${ }^{1}$ Ryan McBride, ${ }^{6}$ Valle Palomo, ${ }^{4}$ Kevin M. Self, ${ }^{1}$ Seth Taylor, ${ }^{2}$ Adriana Irimia, ${ }^{3}$ \\ Sanjay R. Mehta, ${ }^{7,8}$ Jennifer M. Dan, ${ }^{7,9}$ Matthew Brigger, ${ }^{7,10}$ Shane Crotty, ${ }^{7,9}$ Stephen P. Schoenberger, ${ }^{9}$ James C. Paulson, ${ }^{1,6}$ \\ Ian A. Wilson, ${ }^{3}$ Paul B. Savage, ${ }^{2}$ M.C. Finn, ${ }^{5}$ and Luc Teyton ${ }^{1}$ \\ 'Department of Immunology and Microbiology, The Scripps Research Institute, La Jolla, California, USA. ${ }^{2}$ Department of Chemistry and Biochemistry, Brigham Young University, Provo, Utah, USA. \\ ${ }^{3}$ Department of Integrative Structural and Computational Biology, International AIDS Vaccine Initiative Neutralizing Antibody Center, Collaboration for AIDS Vaccine Discovery, Scripps Center for HIV/ \\ AIDS Vaccine Immunology and Immunogen Discovery, and Skaggs Institute for Chemical Biology, The Scripps Research Institute, La Jolla, California, USA. ${ }^{4}$ Department of Chemistry, The Scripps Research \\ Institute, La Jolla, California, USA. ${ }^{5}$ School of Chemistry and Biochemistry, Georgia Institute of Technology, Atlanta, Georgia, USA. ${ }^{6}$ Department of Molecular Medicine, The Scripps Research Institute, \\ La Jolla, California, USA. 'Division of Infectious Diseases, UCSD, La Jolla, California, USA. ${ }^{8}$ Division of Infectious Diseases, San Diego Veterans Affairs Medical Center, La Jolla, California, USA. 'a Jolla Institute \\ for Allergy and Immunology, La Jolla, California, USA. ${ }^{10}$ Division of Otolaryngology, Rady Children's Hospital, San Diego, California, USA.
}

\begin{abstract}
Vaccines targeting glycan structures at the surface of pathogenic microbes must overcome the inherent T cell-independent nature of immune responses against glycans. Carbohydrate conjugate vaccines achieve this by coupling bacterial polysaccharides to a carrier protein that recruits heterologous CD4 T cells to help B cell maturation. Yet they most often produce low- to medium-affinity immune responses of limited duration in immunologically fit individuals and disappointing results in the elderly and immunocompromised patients. Here, we hypothesized that these limitations result from suboptimal T cell help. To produce the next generation of more efficacious conjugate vaccines, we have explored a synthetic design aimed at focusing both $B$ cell and $T$ cell recognition to a single short glycan displayed at the surface of a virus-like particle. We tested and established the proof of concept of this approach for 2 serotypes of Streptococcus pneumoniae. In both cases, these vaccines elicited serotype-specific, protective, and long-lasting IgC antibodies of nanomolar affinity against the target glycans in mice. We further identified a requirement for CD4 T cells in the anti-glycan antibody response. Our findings establish the design principles for improved glycan conjugate vaccines. We surmise that the same approach can be used for any microbial glycan of interest.
\end{abstract}

\section{Introduction}

Over the last 150 years, efficient control of the most dangerous infectious diseases has been achieved through a combination of higher hygiene and the widespread use of vaccines. At a time when immediate control of infections with antibiotics is coming to an end, the development of new vaccines appears a necessity. Because microbial glycans are often chemically distinct from endogenous sugars, and always exposed on the surface of pathogens, they are an attractive target for vaccines (1). The first and second generations of vaccines targeting microbial polysaccharides have had a great clinical impact with a marked diminution of diseases such as pneumonia and meningitis $(2,3)$, but very limited success in the rapidly rising groups of high-risk patients such as the elderly, the chronically ill, and the immunocompromised (4). This situation exposes the current limitations of vaccines that target microbial ligands and is mechanistically linked to one major issue: the modest quality of the $\mathrm{T}$ cell help provided to anti-glycan $\mathrm{B}$ cells in those vaccines.

Authorship note: S. Deng and A. Sarkar contributed equally to this work. Conflict of interest: The authors have declared that no conflict of interest exists. Submitted: October 12, 2016; Accepted: January 19, 2017

Reference information: / Clin Invest. 2017;127(4):1491-1504.

https://doi.org/10.1172/JCI91192.
In their first inception, anti-glycan vaccines were a combination of purified bacterial polysaccharides with a weak adjuvant; their efficacy was reasonable in immunologically fit patients but nearly absent in high-risk groups (5). This inadequacy was easily explained mechanistically: anti-polysaccharide responses are $\mathrm{T}$ cell-independent, dominated by IgM production, do not undergo class switch recombination or affinity maturation, and do not populate the memory compartment (6). Anti-polysaccharide responses are $\mathrm{T}$ independent, because polysaccharides do not bind MHC class II or MHC-like molecules and, therefore, cannot recruit $\mathrm{T}$ cell help.

Thus, mechanistically, the ultimate goal for the design of anti-glycan vaccines is to provide $\mathrm{T}$ cell help to the anti-glycan $\mathrm{B}$ cells (7), to produce higher-affinity antibodies and memory. Some of this was achieved by the second generation of anti-glycan vaccines, also called conjugate vaccines (CVs). In those vaccines, $\mathrm{T}$ cell help was provided by bystander $\mathrm{CD} 4 \mathrm{~T}$ cells in a situation similar to hapten immunization, in which the small molecule is coupled to a carrier protein (8). CVs offer better and longer protection than polysaccharide vaccines, yet do not approach the effectiveness of anti-protein vaccines. This discrepancy is largely explained by the fact that the antibodies elicited by CVs have low affinity for their ligands. It is well known that antibody titers and avidity correlate with protection for protein-based antigens (9), as well as for CVs 
A

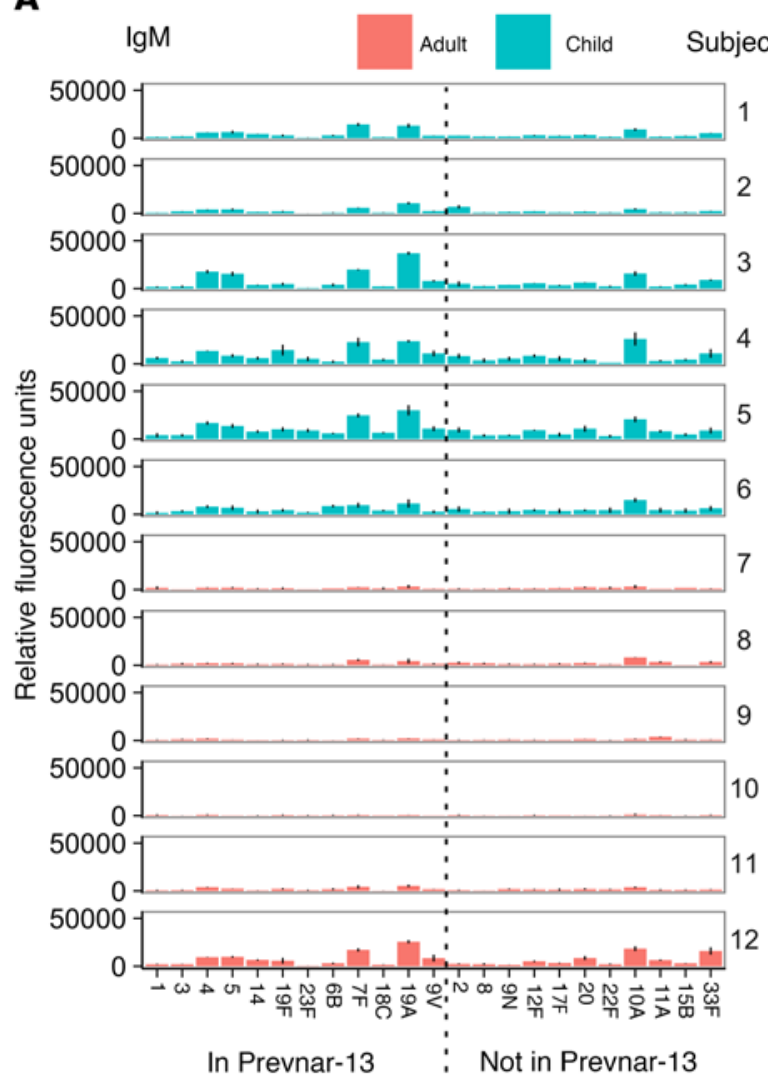

S. pneumoniae serotype

C

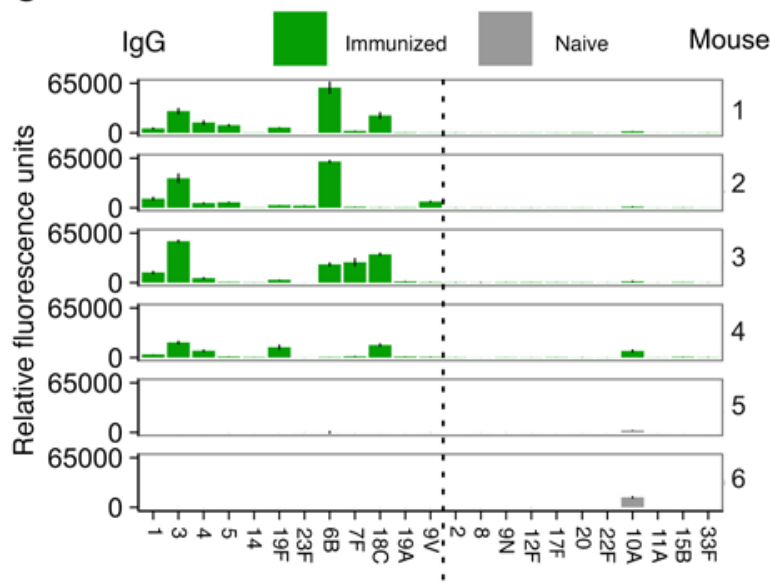

In Prevnar-13 : Not in Prevnar-13

S. pneumoniae serotype

against Haemophilus influenzae (10) and Streptococcus pneumoniae $(11,12)$. To date, all anti-glycan antibodies that have been isolated and characterized have micromolar binding affinity, orders of magnitude lower than anti-protein antibodies elicited by other vaccines (13-19). This impediment of the anti-glycan response is directly linked to the suboptimal maturation of B cells. Since B cell maturation is entirely dependent on cell-cell interactions and cytokines provided by $\mathrm{T}$ cells, it is appropriate to say that CVs would greatly benefit from better $\mathrm{T}$ cell help. A redesign of $\mathrm{T}$ cell help in
B

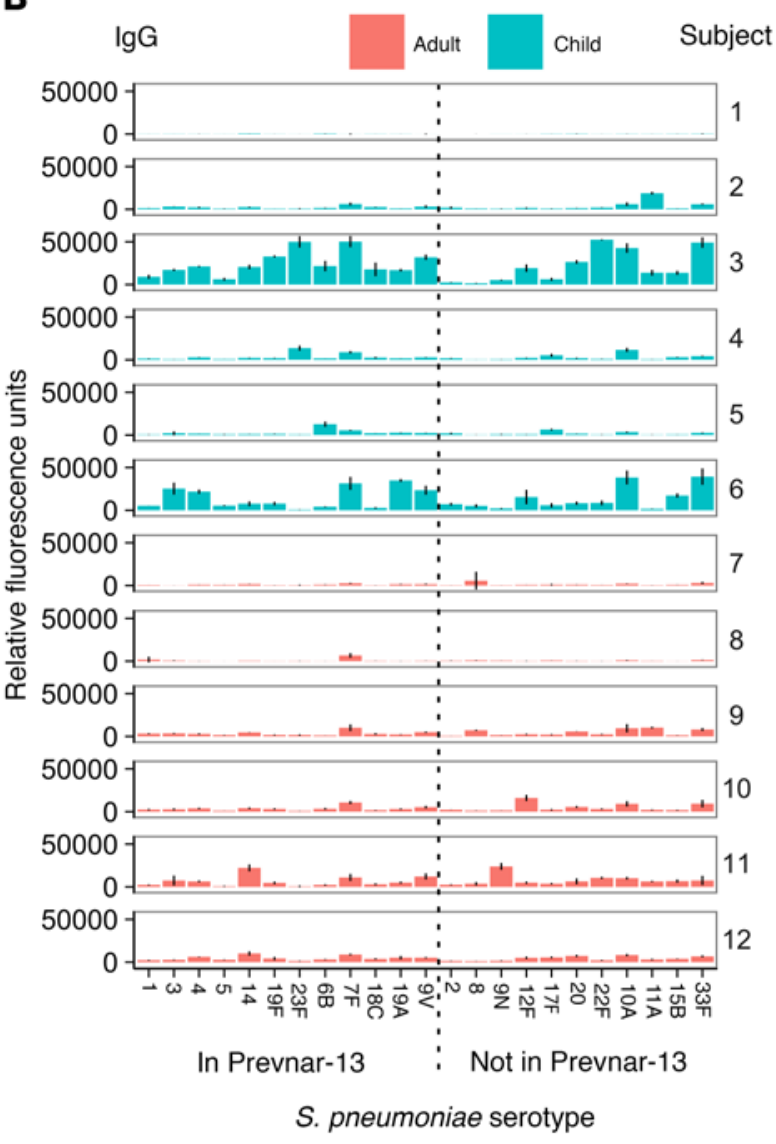

Figure 1. Response of humans and mice to licensed CVs. (A and B) IgM (A) and IgG (B) response in the plasma of 6 pediatric and 6 adult subjects to 23 S. pneumoniae serotype polysaccharides immobilized on a glycan microarray (Supplemental Table 1 and ref. 38). Plasma dilution 1:400. Each graph represents an individual. (C) Response in the sera of mice, immunized with Prevnar-13 ( $n=4$ mice) or naive ( $n=2$ mice), to 23 S. pneumoniae serotype polysaccharides. Each graph represents an individual mouse. Data are presented as the mean \pm SD based on 4 technical replicates.

CVs would lead to higher-affinity antibodies, broader applicability of the approach, and a third generation of very powerful vaccines.

To achieve this goal, we investigated a simple hypothesis: could we use glycans that would be recognized by both $\mathrm{B}$ and $\mathrm{T}$ cells to add to the bystander T cell help of CVs, a degree of cognate $\mathrm{T}$ cell help? The recognition of glycans by $\mathrm{T}$ cells is possible in only 2 contexts: glycolipids, and glycopeptides. We have explored the possibility of increasing anti-glycan B cell help by displaying glycolipids in liposomes to get them presented by $\mathrm{CD} 1$ molecules to $\mathrm{T}$ 

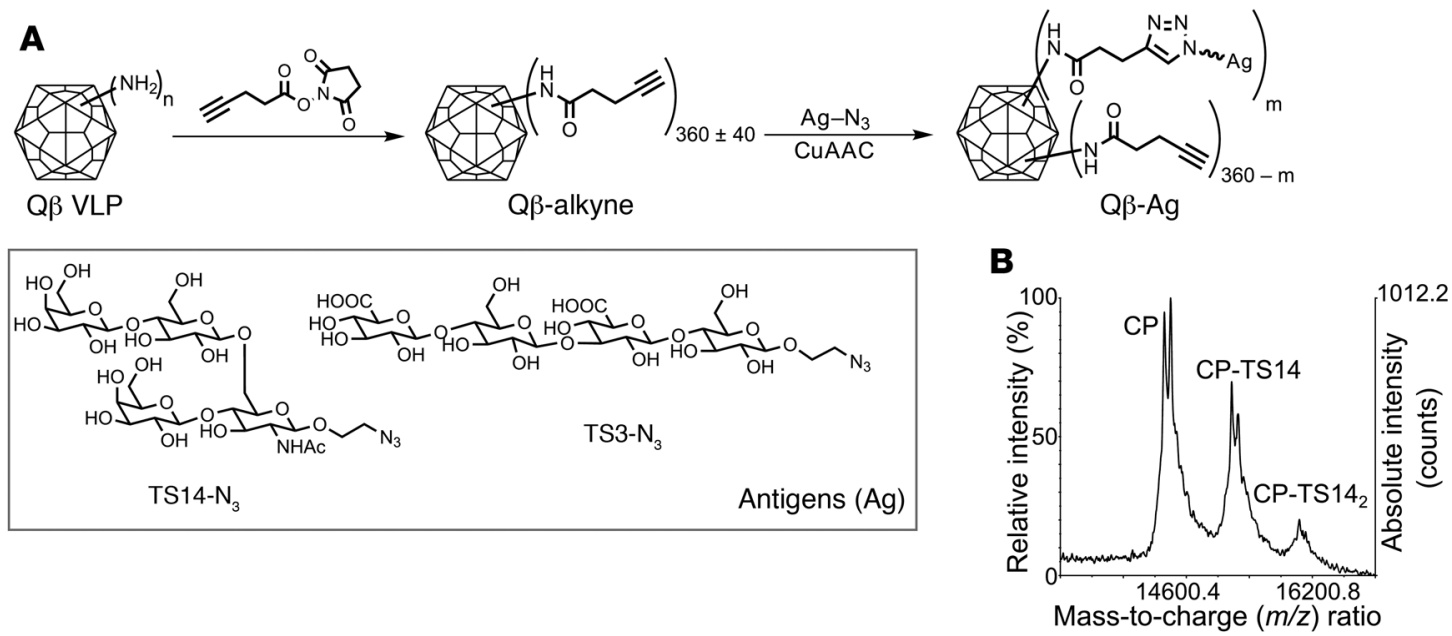

Figure 2. Synthesis of $\mathbf{Q} \beta$-tetrasaccharide conjugates. (A) Synthesis of $Q \beta$-oligosaccharide conjugates. Ag, antigen, i.e., TS3 or TS14; $m$, number of antigens per particle (180 CP subunits). (B) Representative MALDI analysis of Q $\beta$-TS14 ${ }_{80}$. CP, coat protein of Q $\beta$; 180 copies of CP make up 1 Q $\beta$ VLP. CP-TS14; coat protein bearing 1 TS14; CP-TS14 and CP-TS14, coat protein conjugated to 1 or 2 molecules of TS14, respectively.

cells (20). While the approach was successful, it was obvious that the engineering and manufacturing sides of the vaccine formulation were limiting. Therefore, we decided to explore the same principles by displaying glycans on glycopeptides that could be presented by MHC class II molecules to T cells (21-23), and build cognate recognition in addition to carrier $\mathrm{T}$ cell help.

We also knew from in-depth structural studies of $\mathrm{T}$ cell recognition of CD1-glycolipid complexes (24), and functional studies of glycopeptide recognition $(25,26)$, that only small saccharides, from 1 to 4 carbohydrate units, could be accommodated within the binding site of a T cell receptor (TCR) (24), whereas the B cell receptor site could theoretically bind up to 6 units (27). With the only exception of the Cuban anti-H. influenzae vaccine (28), all licensed CVs are produced using purified large natural polysaccharides randomly coupled to a protein carrier $(1,29)$, introducing inherent lot-to-lot variability (29) as well as safety issues. From an immunological standpoint, this mode of coupling cannot result in cognate anti-glycan $\mathrm{T}$ cell help, as the carbohydrate structures are too large and randomly distributed at the surface of the carrier, limiting the possibility that carbohydrate processing in the lysosome could result in a sufficient quantity of homogenous glycopeptides suited for $\mathrm{T}$ cell binding.

Here, we describe what we regard as an entirely new approach to the development of CVs. To increase, qualitatively and quantitatively, $\mathrm{T}$ cell help to anti-glycan $\mathrm{B}$ cells, we designed synthetic glycans that would allow the elicitation of a CD4 glycopeptide response as well as an exquisitely specific B cell response. We achieved this goal by chemically attaching short synthetic glycans to a nanoparticle made of 180 repetitive units assembled in a viruslike particle (VLP). To enhance B cell help further, we included in the formulation of our vaccine one of the most powerful adjuvants known to date, namely an agonist glycolipid of NKT cells $(30,31)$. Indeed, NKT cells have been shown to be central to the differentiation of DCs, the recruitment of naive $\mathrm{CD} 4$ and $\mathrm{CD} 8 \mathrm{~T}$ cells, direct cognate B cell help, and the activation of NK cells (20,32-34).

For proof-of-concept studies, we focused on glycans from a prominent human pathogen, S. pneumoniae, a major cause of mor- bidity and mortality at all ages, but mostly among infants and the elderly (3). Licensed CVs against 7 and 13 invasive S. pneumoniae strains have been successful in the clinic (3), but the efficiency of protection varies widely among serotypes (35) and is limited in the groups of patients that need it the most: the elderly, patients with chronic conditions such as end-stage kidney disease or type 2 diabetes, and immunocompromised individuals. Combined with the failure to develop efficient vaccines against similar capsular polysaccharide targets (36), the incentive to improve CVs and develop a third generation of such vaccines is high.

Here we present one of those third-generation vaccines against $2 S$. pneumoniae pathogenic serotypes. Both formulations elicited long-term protective immunity in mice with exquisite specificity. Protection was due to the induction of very-high-affinity antiglycan antibodies in a completely CD4 $\mathrm{T}$ cell-dependent manner. We believe that these findings define the principles of a new approach to target microbial glycans and constitute the basis for the third generation of CVs.

\section{Results}

Response of humans and mice to pneumococcal CVs. Rarely discussed is the issue of the evaluation of anti-pneumococcal conjugate vaccine (anti-PCV) responses in humans. Unlike in the case of classical protein-based vaccines such as tetanus or diphtheria (9), serum or plasma titers of anti-S. pneumoniae antibodies are rarely determined, as they do not appreciate potential protection. Instead, correlates of protection are usually established in an indirect assay based on opsonization-phagocytosis and killing using macrophage cell lines (37). This situation illustrates well the low quality of the anti-S. pneumoniae immune response following vaccination. We confirmed this by examining the plasma of 6 children (3-10 years after the last scheduled PCV immunization) and 6 healthy adults using a microbial glycan microarray (38). The array displays 313 bacterial sugars, including 23 S. pneumoniae capsular polysaccharides with all but 1 of the serotypes of the current CVs (ref. 39 and Supplemental Table 1; supplemental material available online with this article; https://doi.org/10.1172/JCI91192DS1). As seen in 
A

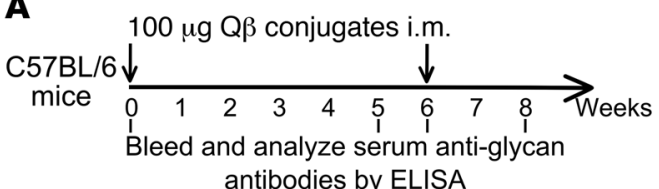

B
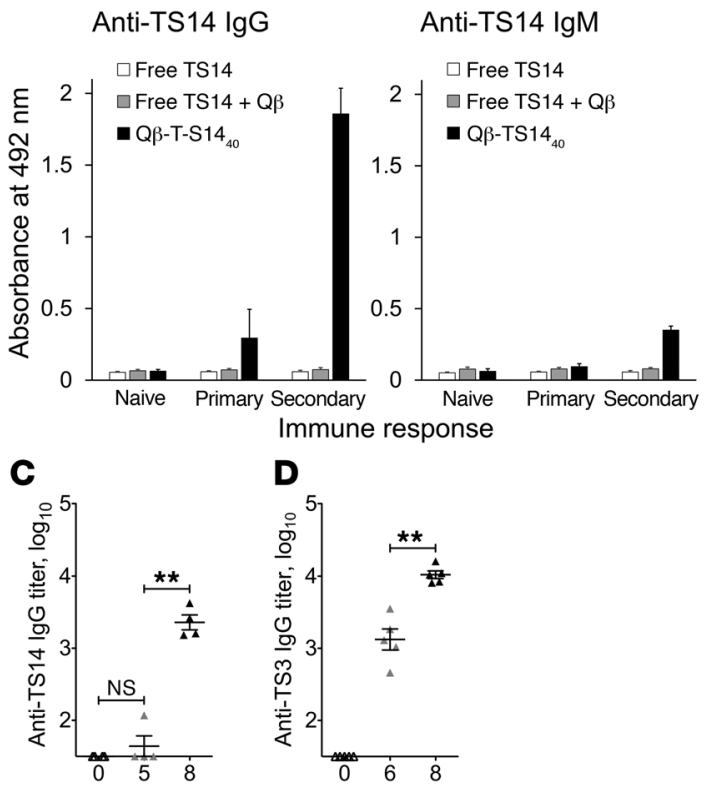

Weeks after primary immunization

E

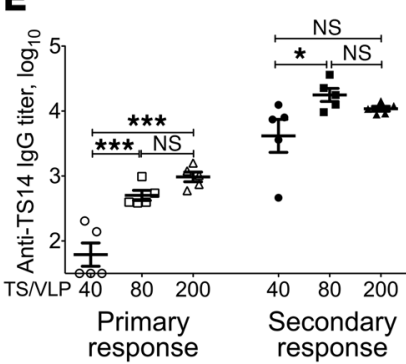

Figure 3. Immunization with $Q \beta$-oligosaccharide conjugates leads to anti-glycan antibody responses. (A) Immunization scheme: mice were immunized i.m. with $100 \mu$ g of $Q \beta$-oligosaccharide conjugates or an equivalent amount of unconjugated oligosaccharides mixed with $500 \mathrm{ng}$ PBS-57. The animals were bled at week 5 or 6 (primary response samples), boosted at week 6 , and bled again at week 8 (secondary response samples). (B) Glycan-specific IgC and IgM in mouse sera (4 per group) measured by ELISA against BSA-TS14. Serum dilution, 1:200. (C) Anti-TS14 IgG titers in mice (4 per group) immunized with $Q \beta$-TS14 ${ }_{40}{ }^{\circ}$ (D) Anti-TS3 IgC titers in mice (5 per group) immunized with $Q \beta-\mathrm{TS}_{160^{\circ}}$ (E) Anti-TS14 IgG titers in mice immunized with $Q \beta$-TS14 conjugates of different density ( 5 per group). Data are representative of at least 2 independent experiments; mean \pm SD values are reported. Statistical significance determined by 1-way ANOVA with Tukey's correction for multiple comparisons. ${ }^{*} P<0.05$; ${ }^{*} P<0.01$; ${ }^{* *} P<0.001$.

Figure 1, A and B, the response to $S$. pneumoniae glycans was weak and highly variable in all cases. In this small sample, only 2 pediatric subjects (\#3 and \#6) showed detectable levels of IgG antibodies against some of the 13-valent vaccine serotypes (serotypes 19A, $19 \mathrm{~F}, 23 \mathrm{~F}, 7 \mathrm{~F})$, but equivalent signals were detected toward serotypes not present in the vaccine (Figure 1). Importantly, some vac- cine-targeted serotypes such as serotype 3 failed to elicit detectable antibody response in any of the subjects, supporting further some post-licensing clinical findings about Prevnar-13 (35).

To complement this observation from humans, we immunized mice with Prevnar-13 (ref. 39 and Figure 1C). Similar to the human situation, the vaccine induced some response in some mice with highly variable anti-serotype distribution (Figure 1). These results exemplify how suboptimal anti-glycan B cell responses manifest themselves in vivo with extreme variability and inconsistency $(4,35)$.

Display of synthetic $S$. pneumoniae oligosaccharides on protein nanoparticles. We decided to tackle this issue directly by designing a new vaccine in which the glycan moiety would be short and synthetic, and attached chemically to a precise site on a protein, to increase the chances of direct recognition of glycopeptides by CD4 T cells. The reasoning behind this design was that it would result in high amounts of homogenous processed glycopeptides, and a facilitated processing and presentation of this/these glycopeptide(s) through receptor-mediated endocytosis by antigenspecific B cells.

Such a synthetic vaccine was produced for both serotypes 3 and 14 of $S$. pneumoniae. Those serotypes were chosen, not only because they are pathogenic in humans and retained in licensed vaccines, but because the tetrasaccharide repeating unit is linear for one and branched for the other one (TS3 and TS14, respectively) (40), making them prototypic of $S$. pneumoniae serotypes. TS3 is a linear repeat of a disaccharide (Glc $\beta 1-3 \mathrm{GlcA} \beta 1-4 \mathrm{Glc} \beta 1-3 \mathrm{GlcA} \beta 1)$, whereas TS14 (Gal $\beta 1-4 \mathrm{Glc} \beta 1-6[\mathrm{Gal} \beta 1-4] \mathrm{GlcNAc} \beta 1)$ is a branched tetrasaccharide (Figure 2A). Both structures are sufficient to elicit antibodies specific for the bacterial capsule of the corresponding serotypes $(41,42)$.

Both tetrasaccharides were synthesized with a terminal azidoethanol linker to introduce a bioorthogonal azide group addressable by copper-catalyzed azide-alkyne cycloaddition (CuAAC) (Figure 2A and ref. 43). The oligosaccharides were coupled to bacteriophage $\mathrm{Q} \beta$ VLPs. $\mathrm{Q} \beta$ was chosen as the display platform because it is composed of 180 copies of a single 132-amino acid coat protein, and is produced in large quantities by recombinant expression of the protein in E. coli in a process that can easily be made compliant with Good Laboratory Practices/Good Manufacturing Practices (44). Coupling of the glycans was performed in 2 steps, starting with attachment of alkyne groups to approximately 360 of the accessible amines on the VLP surface, followed by CuAAC conjugation of the glycan. The number of tetrasaccharides per particle was controlled by adjustment of the concentration and stoichiometry of the reagents in the CuAAC reaction. The particles were characterized by size-exclusion chromatography (Supplemental Figure 1A) to confirm their integrity after chemical modification, by microfluidic gel electrophoresis (Supplemental Figure 1B), and by MALDI mass spectrometry (Figure 2B) to assess the average density of glycan attachment. Controlled reproducible loading of approximately 20-200 tetrasaccharides per VLP was achieved for both TS3 and TS14.

Immunization with $Q \beta$-TS conjugates produces anti-glycan IgG responses. For initial evaluation of $\mathrm{Q} \beta$-TS conjugates, $\mathrm{C} 57 \mathrm{BL} / 6$ mice were immunized i.m. with 1 of 3 formulations: (a) unconjugated TS14; (b) TS14 mixed with Q $\beta$ VLPs without covalent coupling; or (c) Q $\beta$-TS14 conjugates displaying 40 oligosaccharides per parti- 
A
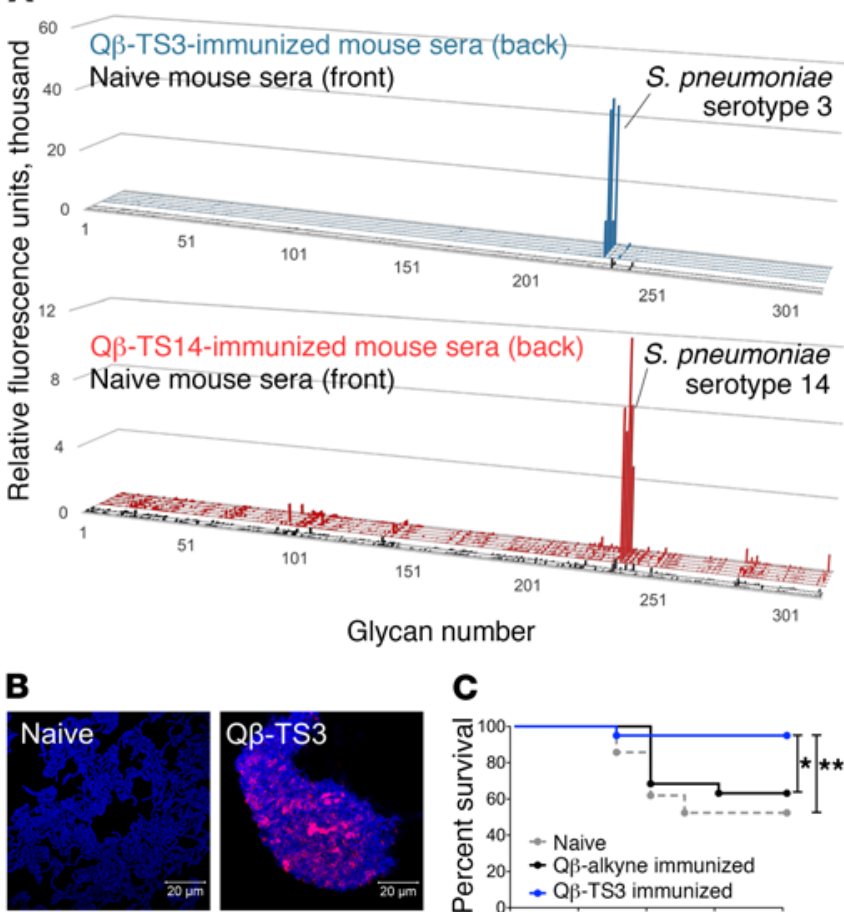

DNA anti-TS3
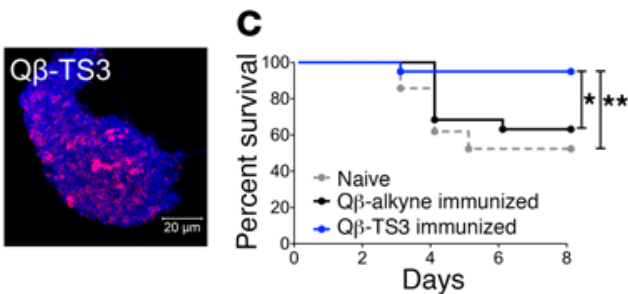

Figure 4. Antibodies against $Q \beta$ conjugates are specific and protective against S. pneumoniae. (A) Sera of 2 naive (black, front, separated by a gap) and 5 Q $\beta$-TS-immunized (color, back) mice were analyzed on microbial glycan microarrays. Each row represents the response of an individual mouse to 313 microbial polysaccharide antigens immobilized on a glass surface. (B) Fluorescence images of S. pneumoniae serotype 14 stained with anti-TS14 antisera. (C) Survival of naive mice or mice immunized with either $\mathrm{Q} \beta$-alkyne or $\mathrm{Q} \beta$-TS3 after i.t. challenge with S. pneumoniae serotype 3. Number of mice: 20 for naive, 19 for $Q \beta$-alkyne immunized, 20 for $Q \beta$-TS3 immunized; data were pooled from 4 independent experiments. Statistical significance was determined by Mantel-Cox test with Bonferroni's correction for multiple comparisons. ${ }^{*} P<0.05$; ${ }^{* *} P<0.01$.

cle $\left(\mathrm{Q} \beta-\mathrm{TS} 14_{40}\right)$, all in the presence of the NKT cell adjuvant PBS57 (Supplemental Figure 1C). The immunization was followed by an i.m. boost with the same formulation 6 weeks later (Figure 3A). Anti-glycan antibody responses were measured by ELISA using TS14 conjugated to BSA to eliminate anti-carrier response as well as possible anti-linker reactivity (Supplemental Figure 2A). Only mice immunized with TS14 covalently attached to Q $\beta$ developed detectable anti-TS14 IgM and IgG antibodies (Figure 3B), while all the animals immunized with $\mathrm{Q} \beta$ VLPs (coupled or not coupled to the sugar) produced anti- $\mathrm{Q} \beta$ antibody responses (data not shown). Both the anti-glycan IgG levels and titers in mice immunized with the conjugates increased after secondary immunization (Figure 3C). Immunization with $\mathrm{Q} \beta$-TS3 conjugates yielded similar results (Figure 3D and Supplemental Figure 2B).

To address the role of oligosaccharide density per VLP in antibody response, mice were immunized with conjugates bearing on average $20,40,80$, or 200 TS14 per particle. No detectable anti-glycan antibody response was produced in mice immunized with $\mathrm{Q} \beta-\mathrm{TS}_{20}$ (data not shown), whereas $\mathrm{Q} \beta-\mathrm{TS} 14_{40}$ elicited some variability in both the primary and the secondary responses (Figure 3E). In contrast, conjugates with higher glycan densities produced similarly potent antibody responses in all animals (Figure 3E). This type of threshold effect was observed previously for the Tn glycopeptide antigen displayed on Q $\beta$ VLPs (45). All subsequent immunizations were carried out with conjugates bearing at least 80 sugars per VLP.

Anti-glycan antibodies bind S. pneumoniae and protect mice against $S$. pneumoniae challenge. To evaluate the recognition of native bacterial capsular polysaccharides by anti-glycan antibodies and its specificity, we used microbial glycan microarrays (Supplemental Table 1 and ref. 38). Both Q $\beta$-TS3 and Q $\beta$-TS14 conjugates generated IgG responses specific for $S$. pneumoniae serotype 3 and $S$. pneumoniae serotype 14 polysaccharides (Figure 4B). The glycan array also revealed remarkable specificity of responses to $\mathrm{Q} \beta$-TS conjugates: while naive mouse sera did not show reactivity to any microbial glycan, sera from mice immunized with TS3 and TS14 conjugates specifically recognized the natural polysaccharides of the corresponding bacterial serotype (Figure 4B), with no measurable cross-reactivity to the other 312 bacterial polysaccharides on the array. Notably, in opposition to our synthetic vaccine, immunization with Prevnar-13 did not consistently elicit antibodies against the tetrasaccharide of either serotype 3 or 14 in either mice or humans (Supplemental Figure 2, C-E).

Recognition of native capsular polysaccharides after $\mathrm{Q} \beta$ oligosaccharide immunization was further confirmed by staining of heat-inactivated $S$. pneumoniae with the sera from animals immunized with $\mathrm{Q} \beta-\mathrm{TS} 14_{80}$ or $\mathrm{Q} \beta-\mathrm{TS}_{160}$, with detection by fluorescence microscopy. Sera of immunized, but not naive, mice bound intact $S$. pneumoniae of the corresponding serotype (Figure 4A and Supplemental Figure 3A). This result was confirmed by transmission electron microscopy with anti-S. pneumoniae serotype $14 \mathrm{mAb}$ 14.22, discussed below (Supplemental Figure 3B).

The antibacterial and protective properties of these antibodies were tested in 2 models of bacterial infection. Because S. pneumoniae serotype 14 is nonpathogenic in immunocompetent mice (46), antibodies raised against TS14 were used for passive immunization of NOD/SCID mice, which were then infected with S. pneumoniae serotype 14 by intratracheal (i.t.) inoculation. Ten of 29 animals in the control group failed to resolve infection and died within 5 days (66\% survival). In contrast, only 3 of 29 mice injected with the antiTS14 mAb 14.22 died (90\% survival) (Supplemental Figure 3C). At day 5 after infection, 12 of 19 surviving control mice harbored lung bacteria, compared with only 6 of 26 in the 14.22-injected group, indicating a high level of sterilization (Supplemental Figure 3D). In a prophylactic immunization model, Q $\beta$-TS3-immunized C57BL/6 mice were protected (95\% survival; Figure 4 C) upon i.t. challenge with $S$. pneumoniae serotype 3 , which is pathogenic in mice, whereas over $40 \%$ of sham-immunized and naive animals died within 7 days.

Glycan-specific B cells undergo class switch and form immunological memory. The isotypes of IgG responses are faithful indicators of the degree of $\mathrm{CD} 4 \mathrm{~T}$ cell help (47). Immunization with the $\mathrm{Q} \beta$-TS14 ${ }_{40}$ conjugates produced a typical T-dependent profile with dominance of $\operatorname{IgG} 2 \mathrm{~b}$ and $\operatorname{Ig} \mathrm{G} 2 \mathrm{c}$ isotypes (Figure $5 \mathrm{~A}$ ). As expected, an increase in sugar density $\left(\mathrm{Q} \beta\right.$-TS14 ${ }_{80}$ and $\mathrm{Q} \beta$-TS14 $\left.{ }_{200}\right)$ led to the emergence of less T-dependent isotypes such as IgG1 and IgG3 (48). The second best indicator of efficient $\mathrm{T}$ cell help is the quality of the induced B cell memory (47). The presence and relative size of the anti-glycan B cell memory compartment were estimated in mouse 
Table 1. Characterization of anti-TS14 mAbs isolated from Q $\beta$-TS14 ${ }_{80}$-immunized mice: 1:1 binding kinetic model

\begin{tabular}{|c|c|c|c|c|c|}
\hline Name & Isotype & $\begin{array}{c}\text { Avidity, nM, } \\
\text { BSA-TS14 }\end{array}$ & $k_{o n}, 10^{4} M^{-1} s^{-1}$ & $k_{\text {off }}, 10^{-5} s^{-1}$ & $\begin{array}{c}\text { Avidity, nM, } \\
\text { lipid-TS14 }\end{array}$ \\
\hline 14.13 & $\lg G 2 b$ & 1.7 & 3.7 & 6.3 & 62 \\
\hline 14.17 & $\lg \mathrm{G} 2 \mathrm{~b}$ & 9.4 & 9.4 & 8.8 & 3,800 \\
\hline 14.18 & $\lg G 2 b$ & 9.9 & 5.5 & 5.5 & 25 \\
\hline 14.20 & $\operatorname{lgG} 2 b$ & 0.79 & 3.9 & 3.1 & ND \\
\hline 14.21 & $\lg G 2 b$ & 0.34 & 4 & 1.4 & 2.7 \\
\hline 14.22 & $\lg \mathrm{G} 2 \mathrm{~b}$ & 0.39 & 5.3 & 2 & 2 \\
\hline
\end{tabular}

Biacore T200 Evaluation software was used to estimate kinetic and affinity constants. ND, not determined.

spleen 2-4 months after secondary immunization with Q $\beta$-TS14 conjugates using an enzyme-linked immunospot assay. On average (5 experiments), 1 in 1,000 splenocytes was antigen-specific (Figure $5 \mathrm{~B})$. The quality of the memory compartment was confirmed by comparison of the titers of the anti-glycan antibodies 8 and 65 weeks after primary immunization. On average, midpoint titers diminished by only 1 order of magnitude, and were still higher than 1:100 in 6 of 8 animals (Figure 5C). We concluded from these series of experiments that the anti-glycan $B$ cells recruited by the $\mathrm{Q} \beta$ conjugate vaccine received high-quality $\mathrm{T}$ cell help.

Glycan-specific antibodies of very high affinity. To further characterize the antibody response to glycans, we produced TS3- and TS14-specific B cell mAbs from immunized mice. Most anti-TS3 antibodies were IgG2c and IgG3, whereas anti-TS14-specific antibodies were predominantly IgG2b (Supplemental Table 2). IgH and IgL cDNAs were sequenced and analyzed using the IMGT, the international ImMunoGeneTics information system database (49). Antibodies against both glycans were derived from very similar germline ancestors (Supplemental Table 2). In all cases, antibodies accumulated nonsynonymous somatic mutations in both heavy and light chains, many of which were localized to the framework regions (Figure 6A, Supplemental Figure 4, and Supplemental Table 2). The only IgM antibody isolated and tested, 14.6, had fewer mutations than the IgG antibodies. Complementaritydetermining regions (CDRs) 1 and 2 of both the heavy and light chains of anti-TS3 and anti-TS14 clones showed multiple amino acid substitutions, but no insertions or deletions. More than half of the anti-TS14 antibodies contained a conserved heavy chain CDR3 (CDRH3) of only 5 amino acids (ARWDY/S) (Supplemental Table 2). Anti-TS3 antibodies had longer CDRH3s on average and often featured a Leu to Arg mutation, which could possibly be beneficial for the recognition of the negatively charged TS3 glycan (Supplemental Figure 4B).

Most anti-TS14 mAbs exhibited nanomolar avidity for the target oligosaccharides, as measured by surface plasmon resonance (Table 1 and 2). The binding kinetics of most mAbs, especially those with the highest avidity $(14.13,14.17,14.18,14.20,14.21$, 14.22), were well fitted using a 1:1 Langmuir equation, most likely indicative of the engagement of a single binding site in the assay format (low antigen density). In all cases, the high avidity was linked to very low off rates (Table 1). In a few cases, antibody bind- ing curves (e.g., 14.2) were best approximated taking into account their bivalent nature; these antibodies had faster off rates (Table 2). The anti-TS3 antibody panel displayed similar characteristics and nanomolar avidities (Supplemental Table 3).

In addition, because the "context" of sugar recognition might be of interest for binding kinetics and neutralization, especially the proximity to a membrane $(50,51)$, we compared antibody binding to sugars attached to proteins and glycan displayed by glycolipids at the surface of liposomes. This assay split anti-TS14 mAbs in 2 categories: antibodies such as 14.22, which retained high avidity regardless of context, and antibodies such as 14.13, which saw their dissociation rates increase when TS14 was presented by a glycolipid (Figure 6B). This result is probably highly relevant in vivo when polyclonal antibodies recognize bacteria at different stages of encapsulation (52).

Fab fragments of high-avidity anti-TS14 and anti-TS3 mAbs, 14.22 and 3.4, were produced for further biophysical characterization. The Fab of mAb 14.22 retained the high affinity of the parent antibody with a $K_{D}$ of $13 \mathrm{nM}$ and a very slow dissociation rate (Table 1 and Figure 6C). This high affinity was confirmed by in-solution competition surface plasmon resonance assays using free TS14azide as competitor (Supplemental Figure 5). Similar numbers, 50 $\pm 2 \mathrm{nM}$, were obtained using isothermal titration calorimetry (ITC) (Figure 6D). Fab3.4 bound TS3 with a measured affinity of $19 \mathrm{nM}$ and kinetic parameters similar to the ones of Fab14.22 (Figure 6C).

The nanomolar affinities of these anti-glycan Fabs are in clear contrast with the commonly observed micromolar affinities of anti-glycan antibodies (19); as such, they represent the first examples of high-affinity anti-sugar antibodies.

Crystal structure of apo-Fab14.22 and its complex with TS14. To understand the molecular basis of this high affinity, the crystal structures of unbound Fab14.22 and its complex with TS14 glycan were determined at $2.2 \AA$ and $1.75 \AA$ resolution, respectively (Supplemental Table 4). Both unliganded and bound forms of Fab14.22 had a very similar structure (C $\alpha$ root-mean-square deviation (RMSD) of the Fv is $0.34 \AA$ ), indicating that the antibody did not require major rearrangements for binding (Figure 7A). Residues at the binding site, as well as the bound glycan, had low $\mathrm{B}$ values (Figure 7B and Supplemental Table 4), further indicative of high complex rigidity and ligand occupancy. TS14 was located on the surface of the combining site between $\mathrm{V}_{\mathrm{H}}$ and $\mathrm{V}_{\mathrm{L}}$, with the branching galactose residue inserted deep into the binding pocket and coordinated by an elaborate hydrogen bond network (Figure 7,

\section{Table 2. Characterization of anti-TS14 mAbs isolated from Q $\beta$-TS14 ${ }_{80}$-immunized mice: bivalent analyte kinetic model}

\begin{tabular}{|c|c|c|c|c|c|}
\hline Name & Isotype & $k_{o n} 1,10^{4} M^{-1} s^{-1}$ & $k_{\text {off }} 1,10^{-2} s^{-1}$ & $k_{o n} 2,10^{-6} R^{-1}$ & $k_{\text {off }} 2,10^{-4} s^{-1}$ \\
\hline 14.2 & IgG1 & 0.76 & 10 & 1.8 & 1.6 \\
\hline 14.6 & IgM & 0.5 & 0.7 & 34 & 3 \\
\hline 14.10 & IgG1 & 3.6 & 5 & 1.4 & 1.5 \\
\hline 14.15 & $\lg G 2 c$ & 3.5 & 3 & 1.4 & 9 \\
\hline
\end{tabular}

Biacore T200 Evaluation software was used to estimate kinetic and affinity constants 
A

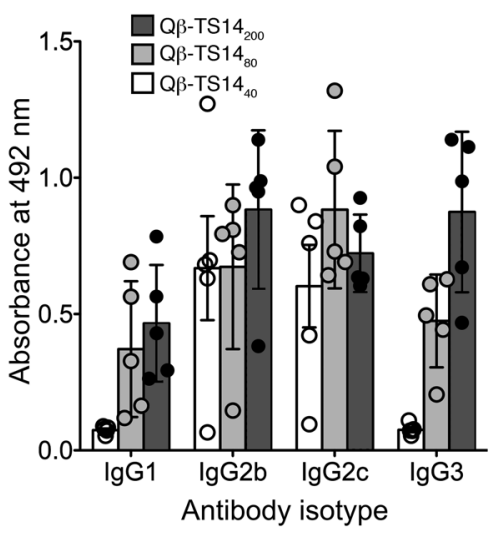

B

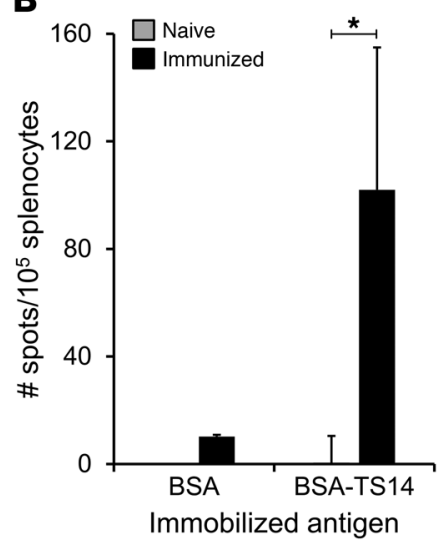

C

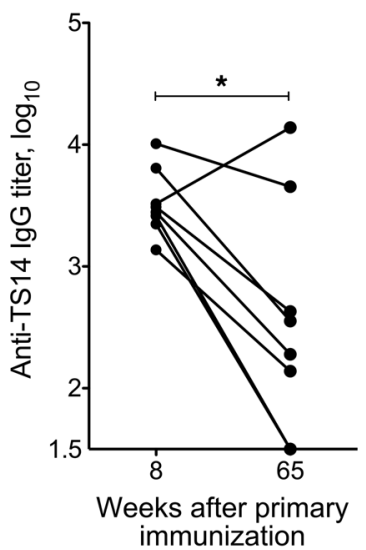

Figure 5. Anti-glycan antibodies undergo class switch and form immunological memory. (A) IgG isotype distribution in mice immunized with $Q \beta$ conjugates of different density. Serum dilution was 1:200. Circles represent results for individual mice (5 per group). (B) Enzyme-linked immunospot analysis of splenocytes from naive and Q $\beta-T S 14_{80}$-immunized mice plated on BSA or BSA-TS14. Number of spots equals antibody-secreting cell count. Results averaged over 5 independent experiments that included 10 mice. (C) Anti-TS14 IgG titers in the blood of mice 8 and 65 weeks after primary immunization. Each circle represents an individual mouse ( 8 mice). Mean \pm SD values are reported. Statistical significance was determined by 2 -tailed Student's $t$ test with unequal variances (B) and paired Student's $t$ test (C). ${ }^{*} P<0.05$.

C and D, and Supplemental Figure 6), burying a surface area of 349 $\AA^{2}$ (calculated using molecular surface [MS]; ref. 53). The binding pocket was made up almost exclusively of aromatic and charged residues (Figure 7D), as observed for other sugar-antibody complexes (13-15). The tetrasaccharide formed a total of 27 hydrogen bonds, 7 of which were directly to residues in the combining site, while 19 were formed with 25 neighboring water molecules and 1 was an intraglycan hydrogen bond. Perhaps surprisingly, the light chain dominated the recognition of the tetrasaccharide (Figure 7C and Supplemental Table 5); $\mathrm{Tyr}_{3} 3^{\mathrm{H}}$ of the CDRH1 was the only heavy chain residue to form a polar contact with the glycan. In addition, hydrophobic contacts between Fab14.22 and the tetrasaccharide were also formed with both heavy and light chain residues (Figure 7D and Supplemental Table 5). This intricate interaction network (Supplemental Figure 6), mediated by well-ordered water molecules that formed an interfacial shell, resulted in a total of 50 hydrogen bonds ( 23 of which were between water molecules), likely accounting for the nanomolar binding affinity of Fab14.22.

$T$ cell help is essential for anti-glycan antibody generation after immunization with $Q \beta$-TS conjugates. From this part of our analysis, we could conclude that our vaccine elicited very-high-affinity B cell responses with isotype and mutation profiles that were indicative of high-quality $\mathrm{T}$ cell help. In our design, $\mathrm{T}$ cell help has 3 likely origins: the innate response and its ability to efficiently recruit $\mathrm{T}$ cells (adjuvants), the carrier protein (VLP, heterologous activation of $\mathrm{T}$ cells), and the direct recognition of glycopeptides (glycan, cognate $\mathrm{T}$ cell help). The relative importance of each was measured in the following set of experiments.

Immunization with $\mathrm{Q} \beta$-TS14 40 in the absence of the NKT cell agonist PBS-57 gave rise to heterogeneous anti-TS14 immune responses, with some animals lacking anti-glycan antibodies even after secondary immunization (Figure 8A). In contrast, the presence of the adjuvant led to consistent high-titer responses. In immunizations using VLPs of very high glycan densities, which confer more $\mathrm{T}$ cell independence (see above), such as $\mathrm{Q} \beta-\mathrm{TS} 3_{160}$, the use of PBS-57 did not confer appreciable improvement in anti- body titers, but we did not examine isotype distribution or mutation rates in this case.

Because $\mathrm{Q} \beta$ VLPs encapsulate bacterial RNA during assembly (54), this type of antigen is assumed to activate Toll-like receptor (TLR) signaling. The role of TLRs was tested by immunization of

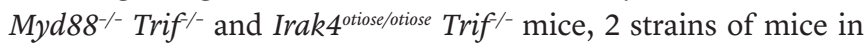
which TLR signaling is impaired, with $\mathrm{Q} \beta$-TS14 40 in the presence of PBS-57. In both cases, the anti-glycan response was markedly reduced, with some animals not responding to the vaccination at all, whereas others had lower levels of TS14-specific IgGs than control animals (Figure 8B). Thus, we concluded that the 2 adjuvants that are retained in our synthetic vaccine, NKT cell adjuvant and TLR ligands, contributed to the level and quality of the anti-glycan B cell responses that we observed.

The direct role of $\mathrm{CD} 4 \mathrm{~T}$ cells was examined by immunization of MHC class II-deficient mice with $\mathrm{Q} \beta$-TS14 ${ }_{40}$ in the presence of PBS-57; it induced no measurable anti-glycan IgG or IgM response (Figure 8C and Supplemental Figure 7). This striking observation demonstrated strict dependence of the observed anti-glycan B cell response on CD4 T cell help. In addition, the subset of $\mathrm{CD} 4 \mathrm{~T}$ cells termed follicular helper $\mathrm{T}$ cells ( $\mathrm{Tfh}$ cells), characterized by the expression of PD-1, CXCR5, and BCL-6, and responsible for B cell help during germinal center (GC) reaction $(55,56)$, was efficiently generated in the secondary lymphoid organs after Q $\beta$-TS14 immunization (Figure 8D). These data in combination with the characteristics of the antibody response described above are suggestive that $\mathrm{Tfh}$ cells are likely involved in the process of anti-glycan B cell maturation, and this issue will need to be addressed directly.

Evidence for glycopeptide-specific $T$ cell involvement. Finally, since glycan conjugates can depart from the hapten-carrier model and support secondary immune responses independent of the nature of the carrier (57), we also wanted to determine whether some percentage of the $\mathrm{T}$ cell help could be provided by cells that recognize the glycan itself. To test whether our vaccine elicited $\mathrm{T}$ cells specific for $\mathrm{Q} \beta$-TS-derived glycopeptides, 11-mer peptides 
A

Heavy chain

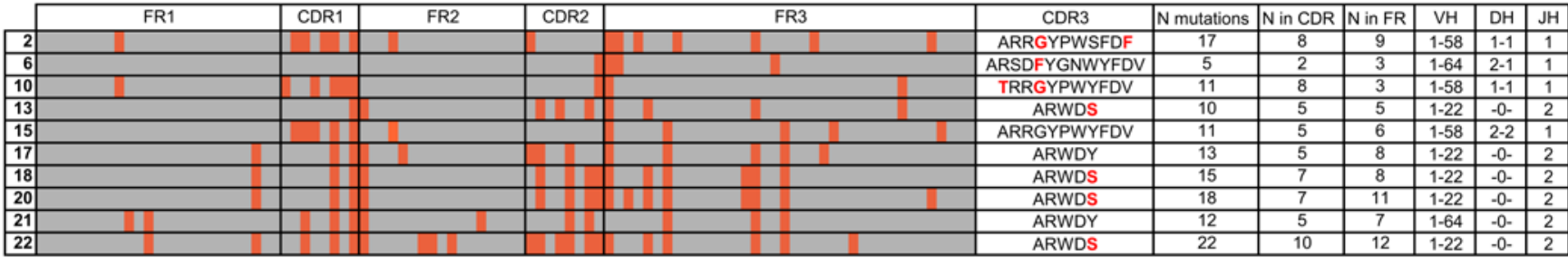

Light chain

CDR2

Genes

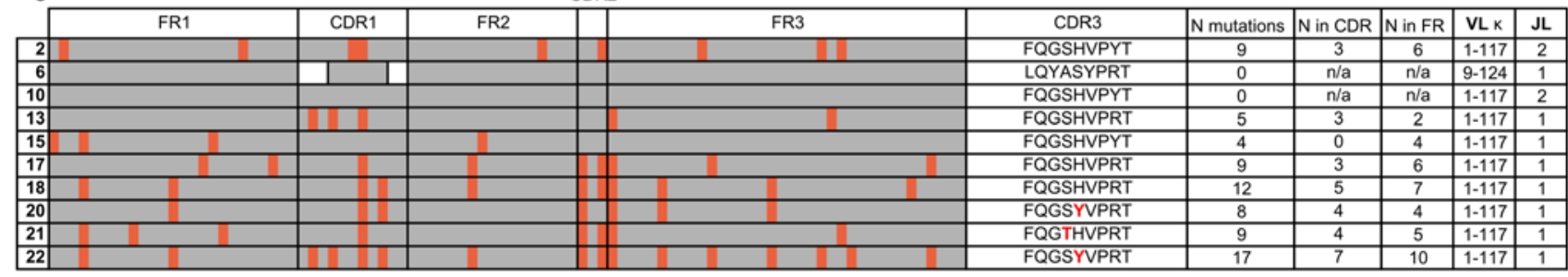

B
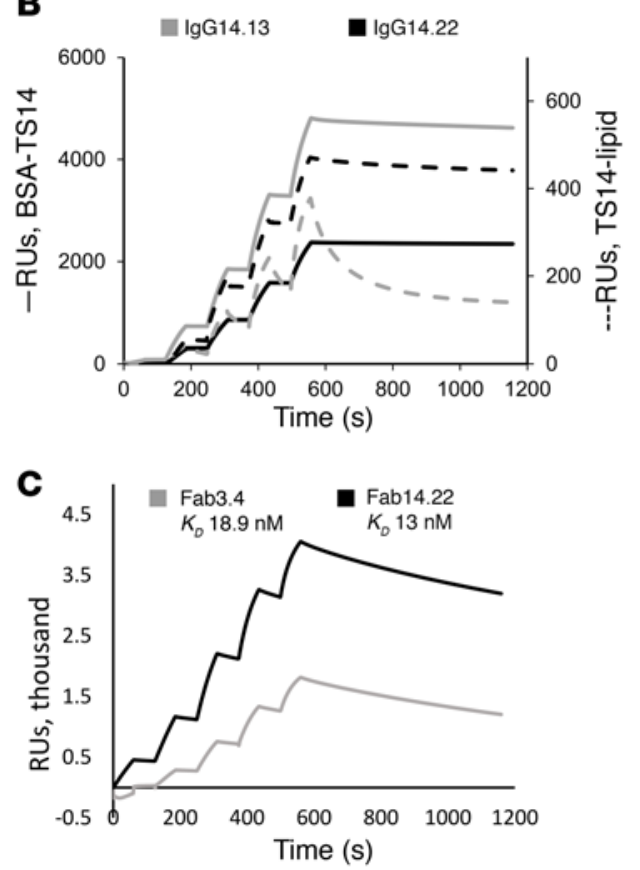

D

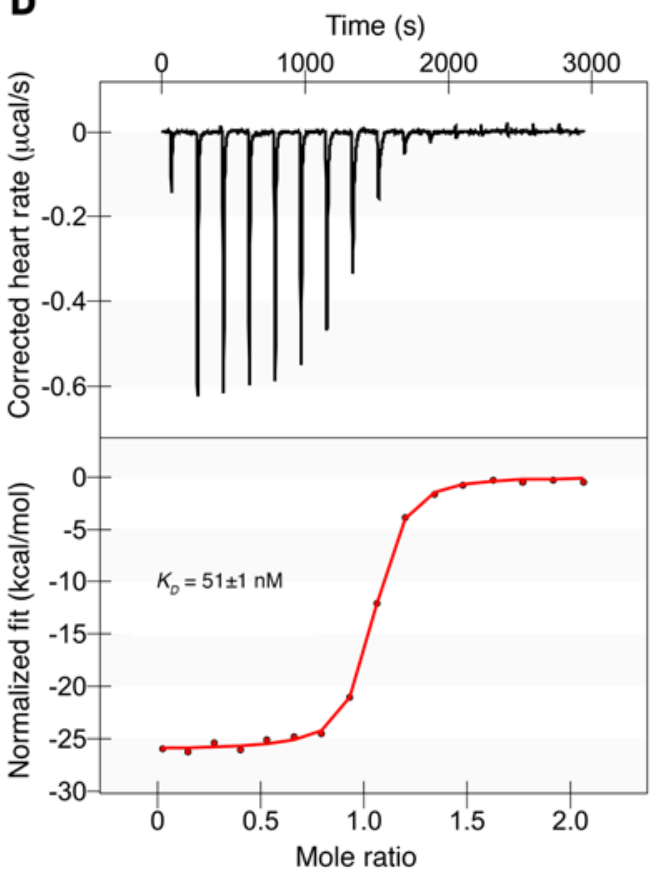

Figure 6. Anti-glycan antibodies accumulate somatic mutations and have high affinity against tetrasaccharides. (A) Mutation distribution in anti-TS14 mAbs. The positions of amino acids mutated from germline sequence are labeled in orange. FR, framework region; CDR, complementarity-determining region, assigned according to the IMGT (83). (B) Surface plasmon resonance (SPR) sensorgrams of antibodies 14.13 and 14.22 binding TS14 presented on BSA or lipid. Five 2-fold dilutions of the antibodies (62.5 nM to $1 \mu \mathrm{M}$ ) were injected sequentially in a single cycle. (C) SPR sensorgrams of Fab fragments of antibodies 3.4 and 14.22 binding BSA-TS3 and BSATS14, respectively. (D) Isothermal titration calorimetry (ITC) analysis of binding of TS14-azide to Fab14.22. Data are representative of at least 2 independent experiments. harboring alkyne-modified lysines K13 or K16 of Q $\beta$ coat protein, the residues most likely to bear the glycan, were synthesized (Figure 9A). After TS14 conjugation to these alkynes, the resulting glycopeptides, denoted gp13 and gp16, were loaded onto recombinant biotinylated $\mathrm{MHC}$ class II I-A ${ }^{\mathrm{b}}$ molecules (58). Binding of glycopeptides to MHC molecules in vitro was confirmed by Western blot with the 14.22 antibody (Figure 9B); TS14 not conjugated to the peptide did not show measurable binding to MHC class II molecules (Supplemental Figure 8, A and B). However, like most peptides binding to I-A molecules, they have low affinity and are likely to be displayed in multiple registers (59). Consequently, using these glycopeptide-loaded MHC class II molecules to produce fluorescent tetramers and direct detection of anti-glycopeptidespecific $\mathrm{T}$ cells gave inconsistent results in identifying the small percentage of glycan-specific CD4 T cells in immunized animals (positive staining in 4 out of 13 experiments; Supplemental Fig- ure $8 \mathrm{C}$ ). While trying to improve this direct detection method, we sought indirect evidence of glycopeptide-specific T cells.

If gp13 and gp16 indeed carried the determinants for both B cell and $\mathrm{T}$ cell recognition, they should sustain by themselves secondary antibody responses and recruit cognate $\mathrm{T}$ cell help. To test this possibility, mice were immunized with $\mathrm{Q} \beta$-TS14 ${ }_{150}$, and then boosted using either the same particle (homologous boost), free TS14 mixed with Q $\beta$ VLPs, or a mixture of 13-mer analogs of gp13 and gp16 glycopeptides, all in the presence of PBS-57 (Figure 9C). As previously shown (Figure 3), the homologous boost resulted in an increase in glycan-specific antibody levels, whereas secondary immunization with the free sugar was ineffective. Recall with the glycopeptides led to a modest but reproducible increase in TS14-specific IgG levels in several animals tested (Figure 9D); no such effect was observed for IgM (Supplemental Figure 9A). The suboptimal efficiency of glycopeptides for driving secondary responses could be explained at least 
A

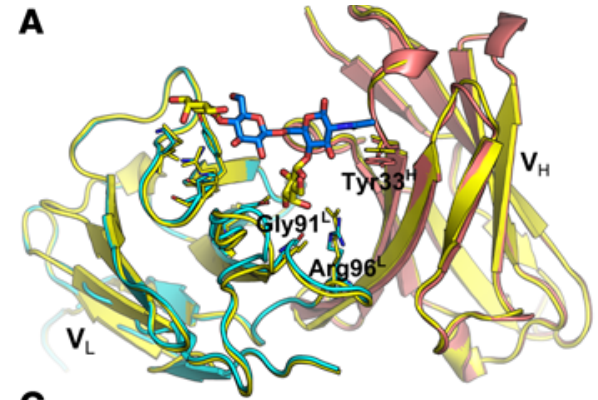

C

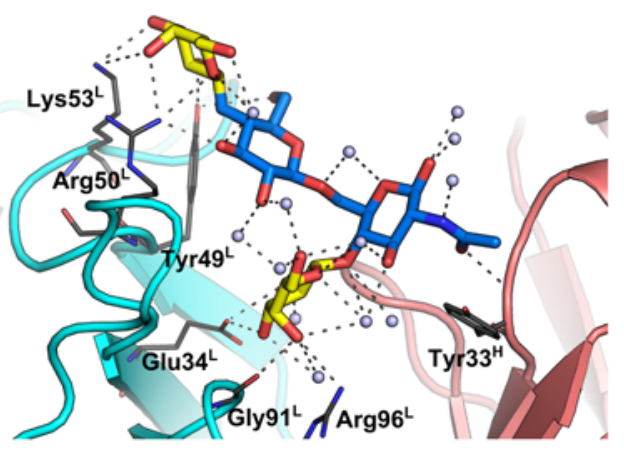

D
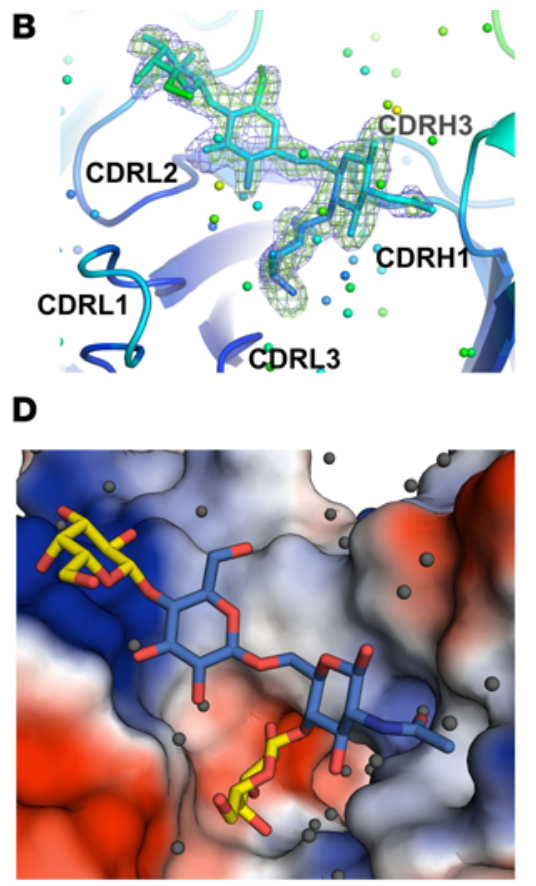

Figure 7. Crystal structure of Fab14.22 in complex with TS14. (A) Superposition of unliganded Fab14.22 (yellow) and Fab14.22 bound to TS14 (cyan, light chain; salmon, heavy chain) shows only minor conformational changes of Gly91 ${ }^{L}$, Arg $96^{\circ}$, and $\mathrm{Tyr} 3^{\mathrm{H}}$ (shown as sticks and labeled). (B) The electron density of TS14 in the antigen binding pocket (2Fo-Fc), contoured at $1 \sigma$ (blue), and the initial positive difference Fourier Fo-Fc map, contoured at $3 \sigma$ (green), with the Fv, TS14 tetrasaccharide and water molecules (spheres) colored according to B values. (C) Hydrogen bond network formed between TS14 and Fab14.22 and well-ordered water molecules at the binding site. (D) Electrostatic surface representation of the binding pocket of Fab14.22 in complex with TS14 tetrasaccharide (color-coded by electrostatic surface potential between -20 and $+20 \mathrm{kT} / \mathrm{e}$ [kT/e: k, Boltzmann constant; T, temperature in Kelvin; e, electron charge] going from red to blue).

in part by the instability of peptides in vivo and/or their low affinity for MHC class II molecules. However, the ability of glycopeptides to boost anti-glycan antibody B cell responses clearly indicated that glycopeptide-specific helper $\mathrm{T}$ cells had been generated after immunization with $\mathrm{Q} \beta$ conjugates; they likely contributed to $\mathrm{B}$ cell maturation. This conclusion was further supported by intracellular cytokine staining of $\mathrm{CD} 4 \mathrm{~T}$ cells from naive and $\mathrm{Q} \beta$-TS14-immunized animals, after in vitro restimulation for 5 hours in the presence of $\mathrm{Q} \beta$ peptides representing 3 regions of the coat protein predicted to bind I-A $\mathrm{A}^{\mathrm{b}}(60)$, or glycopeptides. CD4 T cells making IFN- $\gamma$ and/or TNF- $\alpha$ were detected in immunized, but not naive, animals for both $\mathrm{Q} \beta$ peptides and glycopeptides (Figure 9E and Supplemental Figure 9B). The number of effector cells was very similar for both the carrier, $\mathrm{Q} \beta$, and the nominal glycopeptide antigens in 2 separate experiments.

\section{Discussion}

The few glycan CVs that are currently on the market have had an undeniable impact on the course and frequency of the diseases they target (3). However, it is obvious that a lack of better understanding of the basic aspects of anti-glycan B cell responses has limited their further development and greater success. Two examples best illustrate those limitations. First, if we take the most successful of these CVs, the anti-S. pneumoniae vaccine, its response heterogeneity among subjects and species (35) and its inefficiency in high-risk groups (4) are clear indications that improvements are much needed. Secondly, the failure of StaphVAX (Nabi Biopharmaceuticals) in a second phase 3 clinical trial (36) illustrates how low-affinity antibodies are not sufficient to provide efficient and long-term protection. On this basis, we identified the main issues of CVs as the elicitation of low-affinity antibodies and the production of an insufficient number of memory B cells. Mechanistically, we hypothesized that these 2 weaknesses were linked to a poor quality of the $\mathrm{T}$ cell help to anti-glycan $B$ cells. To address these issues, we attempted to design a synthetic vaccine that would offer the flexibility of addressing each fundamental immunological aspect of the $\mathrm{B}$ cell responses individually.

This effort is presented in the current work, where we establish the proof of principle of a multicomponent synthetic vaccine designed to increase the $\mathrm{T}$ cell dependence of glycoconjugates through multiple mechanisms, and elicit protective long-lasting high-affinity anti-glycan antibody responses. Our improvements on current CVs are (a) the use of adjuvants to engage the innate immune response and facilitate DC activation and presentation, (b) the controlled display of the glycan antigens on an immunogenic nanoparticle, and (c) the short synthetic nature of the oligosaccharides that we used to optimize $\mathrm{B}$ and $\mathrm{T}$ cell recognition. After the short era of polysaccharide vaccines and the longer and more successful one of CVs, we propose the further development of anti-glycan-based vaccines into their third generation.

The value of the adjuvants that we provide in our formulation and that combine TLR signaling and NKT cell activation was shown conclusively in TLR signaling-deficient animals and by omission of the NKT cell agonist. While we know the effect of both adjuvants on the maturation and differentiation of DCs $(33,60)$, the possibility that anti-glycan B cells were also directly targeted by our adjuvant combination will need to be explored further. Indeed, the direct B cell help role of NKT cells has been documented $(20,61,62)$, as has been the role of TLR in B cell differentiation and maturation (63). Operationally, it constitutes a good example of the principle of adjuvant combinations $(33,64)$. It should also be noted that the $\mathrm{Q} \beta$ platform favors efficient DC engagement because of its optimal size for lymphatic trafficking and phagocytic uptake (65).

The logic behind the use of short synthetic glycans instead of native purified polysaccharides comes from 3 complementary arguments. First, the identity of a microbial polysaccharide is structurally defined by di- to tetrasaccharide repeat units with few exceptions extending beyond 4 (38). Second, structural evidence strongly suggests that the TCR cannot accommodate more than 4 glycan units in its binding site $(23,24)$. Third, synthetic glycans eliminate the regulatory and safety concerns brought by natural polysaccha- 
A

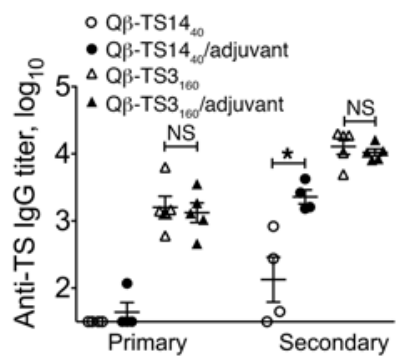

C

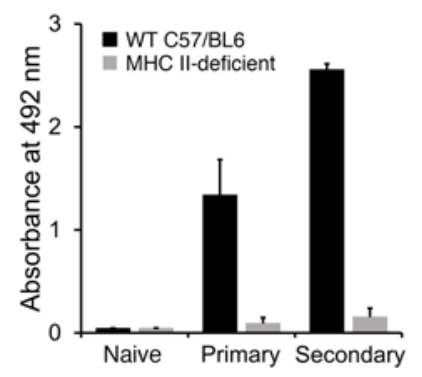

B

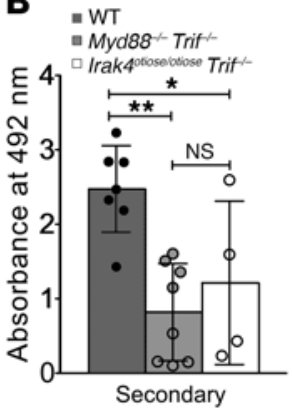

D

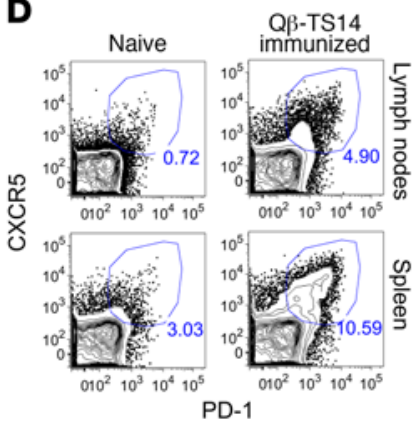

Figure 8. Innate immune signaling and cognate CD4 T cells are essential for anti-glycan antibody responses. (A) Anti-glycan IgC titers in the sera of mice (4-5 per group) immunized with $Q \beta$ conjugates with and without NKT adjuvant PBS-57. Open symbols, formulations without adjuvant; closed symbols, formulations with 500 ng PBS-57 per mouse. (B) Anti-TS14 secondary lgG response measured in the sera of WT and TLR signaling-impaired mice at serum dilution 1:200. Number of mice: 5

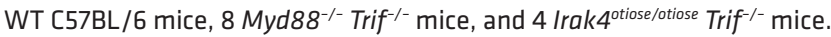
(C) Anti-TS14 IgG response measured in the sera of WT and MHC class II-deficient mice at serum dilution 1:200 (5 per group). (D) Detection of Tfh cells in spleen and draining lymph nodes of a naive mouse (left) and after secondary immunization with $Q \beta$-TS14 (right). The population gated on live

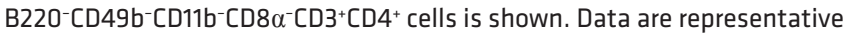
of more than 5 independent experiments. Mean \pm SD values are reported. ${ }^{*} P<0.05,{ }^{* *} P<0.01$, by 2 -tailed Student's $t$ test (A) or 1-way ANOVA with Tukey's correction for multiple comparisons (B).

rides: production, heterogeneity, batch-to-batch consistency, difficulty of quality control, contamination. Other groups are exploring similar approaches $(29,45,66,67)$. In the present case, the validation of the choice to use short glycans came from the examination of the polyclonal antisera against the 2 synthetic sugars using the glycan microarray (38). Indeed, in both cases, exquisite specificity of response was demonstrated for each individual mouse with no appreciable reactivity against any of the other 312 other bacterial polysaccharides. This success contrasts with the results obtained from the immunization of mice with Prevnar-13, which showed heterogeneity in the B cell response against all 13 serotypes.

The application of the general principles that we applied in our design resulted in both exquisite specificity and unprecedented high affinity of anti-glycan antibodies. The role of $\mathrm{T}$ cells in this result was demonstrated by the isotype profile of the $\mathrm{B}$ cell response, and the high number of somatic mutations in both heavy and light chains of the antibodies. As a large proportion of those somatic mutations is in framework regions, we can propose that the selection of higher binders was driven by orientation and configuration more than by a classic optimization of the binding

site residues in direct contact with the antigen (68). The oligoclonality of the $\mathrm{B}$ cell response that we observed for both serotypes is difficult to interpret, as it is common for immune responses to both proteins and glycans (69), as well as haptens (70). The examination of a large number of anti-glycan $B$ cell responses will be needed to extract the significance of this feature.

The quality of anti-glycan B cell response to our synthetic vaccines was confirmed by examination of individual mAbs. Many of these antibodies demonstrated nanomolar dissociation constants, a feature that is unprecedented in the published reports of anti-glycan antibodies, which until now have displayed micromolar affinity $(13-16,18,19)$. From a clinical standpoint, low affinity of anti-carbohydrate antibodies likely contributes to the limited efficacy of CVs. Correlation between high antibody affinity and function has been firmly established for protein targets, such as toxins and viruses $(71,72)$. This explains why for glycan vaccines, currently used correlates of protection, such as specific antibody concentration and opsonophagocytic titer (37), are poor predictors of vaccine efficacy $(73,74)$. A correlation between antibody avidity and protection has been observed in some instances for CVs (10-12), but it could not be translated into a validated in vitro test, as the correlation was too weak and the variations between individuals too high. It is likely that in our case, antibody titers would be predictive of protection as they are for anti-protein vaccines.

The structure of the 14.22 Fab fragment delivered the first information on how high affinity was achieved for the recognition of glycans. The limited conformational changes between free and complexed Fab suggest the selection of a preconfigured binding site. Such a site would most likely favor the on-rate of the binding reaction. This idea is reinforced by the location of some of the somatic mutations in the framework regions that should all optimize orientation and configuration of binding. This issue can be easily addressed by mutagenesis of some residues in the binding site. Given the small size of binding site of 14.22, the water shell that mediated most of the hydrogen bonds between the Fab and the ligand is most likely critical to high affinity (75-77).

In addition, we showed that the optimization of the $\mathrm{T}$ cell help resulted in a large and functional memory B cell compartment. This contrasts favorably with immune responses to existing CVs, which require 3 or more doses and wane over time $(2,4)$. In our case, the magnitude and quality of the B cell memory response is mostly determined by the quality and polarization of $\mathrm{T}$ cell help (47), and the choice of adjuvants (64).

The cognate recognition of the antigenic sugar by CD 4 T cells is, in our view, the most important and least studied part of glycoconjugate vaccines. First mentioned and partially revealed by the studies of Kasper and colleagues (57), the role of glycan-specific $\mathrm{T}$ cells is strongly supported by our work. We believe that small chemical adjustments of glycan display could result in an increase of this cognate help; these hypotheses are currently being tested.

In conclusion, we produced and tested a synthetic vaccine that demonstrated protection against infectious challenges in both a passive immunization setting and a prophylactic situation. The high affinity of the anti-glycan B cell response was driven by a combination of adjuvants and an optimization of $\mathrm{T}$ cell help due to the use of a repetitive display particle and the elicitation of anti-glycopeptide-specific T cells. Given the well-known cor- 
A

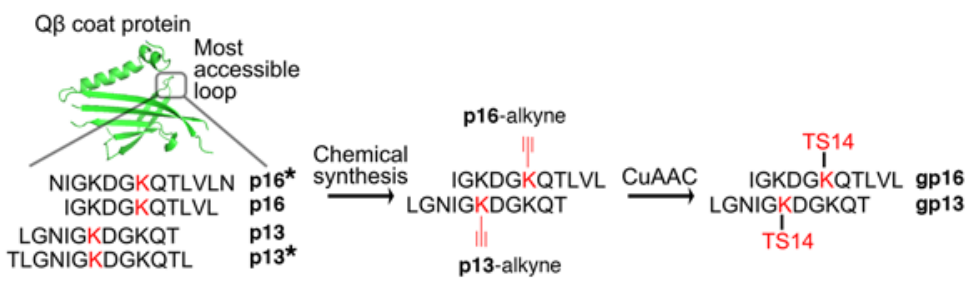

B

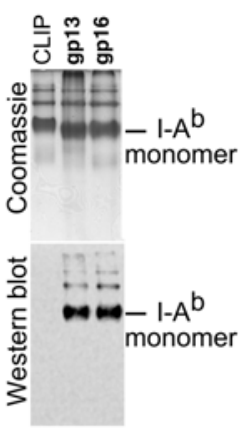

C

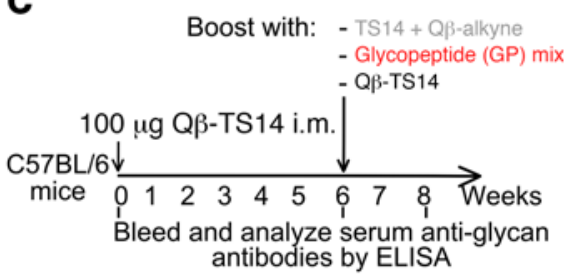

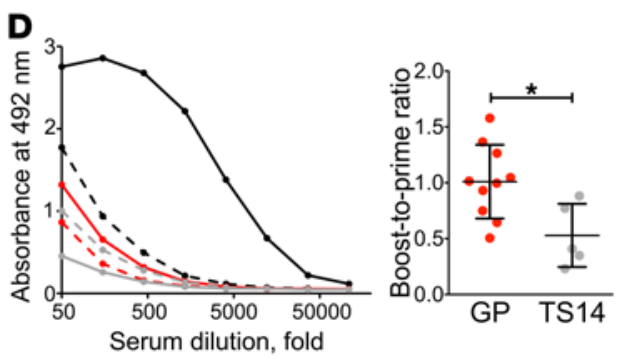

$\mathbf{E}$
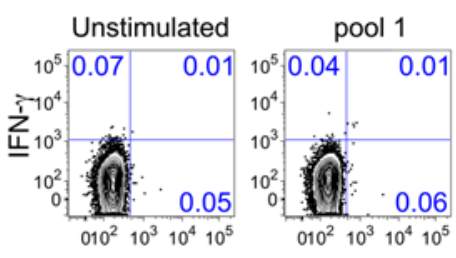

$\mathrm{Q} \beta$ peptides predicted to bind $\mathrm{I}-\mathrm{A}^{\mathrm{b}}$

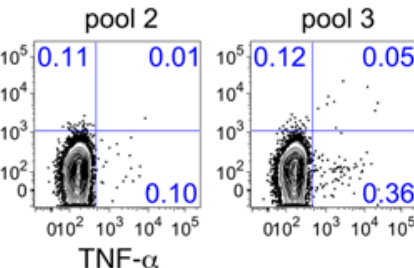

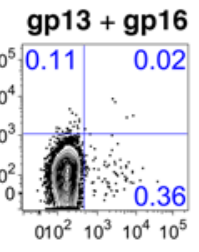

Figure 9. Evidence for the role of glycopeptide-specific CD4 T cells in the response to $Q \boldsymbol{Q}$ conjugates. (A) Design of $Q \beta$-derived 11-mer glycopeptides gp13 and gp16. (B) Coomassie staining and Western blot using IgG14.22, showing gp13 or gp16 I-A complex formation after competition with CLIP placeholder peptide. (C) Scheme of immunization for the heterologous boost experiment. (D) TS14-specific IgGs were measured in post-prime and post-boost sera of immunized mice by ELISA. Left: Dilution curves. Dashed lines, post-prime; solid lines, post-boost. Right: The ELISA signal at 1:50 dilution generated by post-boost sera was divided by the signal from post-prime sera, resulting in a relative increase in antibody levels after boosting. Each dot represents an individual mouse. Number of mice: 5 for free TS14, 5 for $\mathrm{Q} \beta$-TS14, 10 for glycopeptide boost; data were pooled from 2 independent experiments. Mean \pm SD values are reported. Statistical significance was determined by 2-tailed Student's $t$ test. (E) Intracellular cytokine staining of CD4 T cells in the lymph nodes of a $Q \beta$-TS14-immunized mouse after 5 -hour restimulation with the indicated peptides. The population gated on live B220-CD11b-CD8 $\alpha^{-} \mathrm{CDB}^{+}{ }^{+} \mathrm{CD} 4{ }^{+}$ cells is shown. Data are representative of 2 independent experiments. ${ }^{*} P<0.05$. relation of avidity with opsonophagocytic activity and protection in licensed protein-based vaccines, we are optimistic that this third generation of anti-glycan vaccines will impact the management of infectious diseases.

\section{Methods}

Supplemental Methods are available online with this article; https:// doi.org/10.1172/JCI91192DS1.

Plasma donors. Fresh blood was obtained from pediatric patients at Rady Children's Hospital, and from adult normal blood donors at The Scripps Research Institute (TSRI). Informed consent was obtained from all donors under protocols approved by the IRBs of UCSD, the La Jolla Institute for Allergy and Immunology, and TSRI.

Mice. C57BL/6J WT mice were bred locally at TSRI. NOD/SCID mice were purchased from Jackson Laboratory. Myd88 ${ }^{--}$Trif/- mice $(78,79)$ and MHC class II-deficient mice (80) were provided by C. Surh (TSRI, San Diego, California, USA), and Irak4 $4^{\text {otiose/otiose }}$ Trif/- mice (81) were provided by B. Beutler (TSRI, San Diego, California, USA). No randomization or blinding was performed. No animals were excluded from the experiments.

Immunizations and blood draws. Six- to 8-week-old age-matched female mice were immunized i.m. with $50 \mu$ l of Q $\beta$ and TS14 formulations, with the adjuvant mixed with the antigen(s) immediately before immunization. For Prevnar immunizations, animals were immunized i.m. with $50 \mu \mathrm{l}$ (one-tenth human dose) of Prevnar-13 (Wyeth), following the same schedule as for $\mathrm{Q} \beta$-TS immunizations. Blood draws were performed by retro-orbital bleeding. Sera were separated from cells using Microtainer serum separator tubes (BD Biosciences) and frozen at $-20^{\circ} \mathrm{C}$ until analysis.

Large-scale mAb expression and purification. Hybridoma cells were cultured in CELLine flasks (Integra Biosciences) per the manufacturer's instructions. About $100 \mathrm{ml}$ of harvested culture (8 splits) was pooled and centrifuged to remove cells, and supernatants were stored at $4^{\circ} \mathrm{C}$. Before purification the pooled supernatants were filtered using a $0.22-\mu \mathrm{m}$ filter and loaded on a Protein G column (GE Healthcare) overnight. On the next day, the bound antibodies were eluted using $100 \mathrm{mM}$ Tris-glycine, $\mathrm{pH}$ 2.5, and immediately neutralized using $1 \mathrm{M}$ Tris, $\mathrm{pH} 10$. The antibody solution was dialyzed overnight against PBS.

Surface plasmon resonance measurements with immobilized proteins. One thousand five hundred resonance units of TS14-BSA or the antibodies were covalently bound to a Biacore CM5 sensor chip (GE Healthcare) using standard amine coupling. Analyte was injected onto the surface at a flow rate of $30 \mu \mathrm{l} / \mathrm{min}$ in successive 2-fold dilutions from $62.5 \mathrm{nM}$ to $1 \mu \mathrm{M}$ in single cycle mode, followed by regeneration using $50 \mathrm{mM}$ diethylamine in $200 \mathrm{mM} \mathrm{NaCl}$. Experimental curves were normalized by subtraction from a reference surface (immobilized BSA or irrelevant antibody). Sensorgrams were analyzed using BIAevaluation 3.0 software (GE Healthcare) and fit globally to determine kinetic constants. The fit was evaluated based on $\chi^{2}$ values and the appearance of residuals.

Surface plasmon resonance measurements with immobilized liposomes. The general procedure for liposome formulation was as pre- 
viously described (82). DPPC, cholesterol, DPPG, and PBS150, all in chloroform, were mixed at a weight ratio of 60:19:20:1. After evaporation of the solvent under a stream of nitrogen gas, lipids were dried for 2 hours in a Savant evaporator. The lipid film was rehydrated at $65^{\circ} \mathrm{C}$ in PBS at a concentration of $1 \mathrm{mg} / \mathrm{ml}$. The suspension was extruded 11 times through 100-nm polycarbonate membranes using a miniextruder (Avanti Polar Lipids). Stock liposome suspension was stored at $4^{\circ} \mathrm{C}$. The liposomes were noncovalently immobilized on Biacore L1 chips, and subsequent analysis performed as described above for immobilized proteins.

Isothermal titration calorimetry. ITC was carried out on MicroCal Auto-iTC200 (Malvern Instruments Ltd.). 10.4 mM Fab14.22 in PBS was deposited in the cell (initial volume $199.7 \mu \mathrm{l}$ ), and $104 \mathrm{mM}$ TS14azide was added to the cell in 16 injections (injection volume $2.5 \mu \mathrm{l}$, initial injection $0.5 \mu \mathrm{l}$ ), at $25^{\circ} \mathrm{C}$. The enthalpy of reaction, $\Delta H$, the binding constant, $K_{D}$, and the stoichiometry value, $n$, were calculated from the measured heat changes upon association of TS14 with Fab14.22. Curve fitting was performed using NanoAnalyze software (TA Instruments).

Microbial glycan array analysis. The microbial glycan arrays were produced as previously described (38). Mouse sera, diluted 1:5,000 in PBS-Tween, were applied directly to the array surface, incubated for 1 hour in a humidified chamber, and washed, by dipping, in PBS-Tween. The slide was then incubated with goat anti-mouse IgG, Alexa Fluor 488 (Invitrogen) diluted to $10 \mu \mathrm{g} / \mathrm{ml}$ in PBS-Tween, for 1 hour at room temperature followed by washing and detection of fluorescence with a microarray scanner (Innoscan 1100AL, Innopsys). The integrated spot intensities were determined using Mapix software (Innopsys).

Infection of $C 57 \mathrm{BL} / 6$ mice with $S$. pneumoniae serotype 3. Mice were immunized twice with Q $\beta$-alkyne (sham), or Q $\beta$-TS3, with PBS-57, as described in Figure 3A. At week 9 to 11 the immunized and agematched naive animals were infected i.t. with approximately 2,500 to $3,500 \mathrm{CFU}$ of $S$. pneumoniae serotype 3 , and the disease progression was followed by monitoring of weight changes for 7 days.

Infection of NOD/SCID mice with S. pneumoniae serotype 14. Both male and female mice 2-6 months of age were used in the experiments. The animals were matched between treatment and control groups based on sex, age, and weight at the beginning of the experiment. A day before infection the animals were injected i.p. with PBS or $200 \mu \mathrm{g}$ 14.22. Bacteria were grown to log phase in liquid culture 3 times to achieve a high degree of encapsulation. $\mathrm{OD}_{600}$ of the final passage was measured, and approximate CFU per milliliter calculated. The bacterial suspension was washed with PBS and diluted to $4 \times$ $10^{8} \mathrm{CFU} / \mathrm{ml}$. Fifty microliters of bacterial suspension $\left(2 \times 10^{7} \mathrm{CFU}\right.$ per mouse) was administered i.t. to anesthetized mice. The exact bacterial load per mouse was verified by plating of the bacterial suspension on blood agar plates. The animals were monitored for 5 days, and their weight recorded as a readout of disease progression. After 5 days, the lungs of surviving mice were extracted and homogenized, and the bacterial burden was evaluated by plating of serial dilutions of the homogenates on blood agar plates.

Statistics. Statistical significance was determined using the unpaired, 2-tailed $t$ test with Welch's correction for single comparisons, or 1-way ANOVA with Tukey's test for multiple comparisons and Bartlett's test for similar variances when sample sizes were large enough, unless otherwise specified in the figure legend (Prism; GraphPad Software Inc.). Mean \pm SD values are reported. In all experiments, differences were considered significant when $P$ was less than 0.05 .
${ }^{*} P<0.05 ;{ }^{* *} P<0.01 ;{ }^{* *} P<0.001$. For titer determination, serial dilution curves were fitted with the 4-parameter sigmoidal model (BioDataFit; Chang Bioscience Inc.). The titers were determined as $\log _{10}$ of the dilution that gives a half-maximal signal in an ELISA assay. A value of 1.5 was assigned to titers that were too low to estimate from experimental data for statistical evaluation.

Study approval. All experimental procedures involving animals were performed per TSRI institutional guidelines and were approved by TSRI IACUC. Informed consent was obtained from all donors under protocols approved by the IRBs of UCSD, the La Jolla Institute for Allergy and Immunology, and TSRI.

\section{Author contributions}

ZP, MCA, PBS, MGF, and LT designed the study. ZP, AS, LK, MCA, and LT conducted the experiments. SD, CSM, KK, MH, VP, KMS, ST, SRM, JMD, MB, SC, and SPS provided compounds and materials. AS, AI, and IAW solved crystal structures. RM and JCP performed microarray analyses. ZP, MGF, and LT wrote the manuscript. ZP, AS, SC, JCP, IAW, PBS, MGF, and LT edited the manuscript.

\section{Acknowledgments}

We thank Robyn Stanfield, Xiaoping Dai, and Marc Elsliger for discussions and suggestions regarding the crystal structures, Henry Tien for technical support with crystallization robots, John Teijaro for help with intratracheal infections, Malcolm Wood for transmission electron microscopy images, Anne Costanzo for help with fluorescence microscopy, Darina Spasova and Christopher Martin for help with intracellular cytokine staining, and Marisa L. Martino for critical reading of the manuscript. This work was supported by Marie Curie Actions grant VLPsiRNA-FP7-PEOPLE-2009-IOF-254069 to MCA, NIH grants R21 AI129871 (to LT), R01 GM101421 (to MGF), and R01 AI084817 (to IAW), and the Scripps Center for HIV/AIDS Vaccine Immunology and Immunogen Discovery (UM1 AI100663), and was partially funded by the International AIDS Vaccine Initiative (IAVI) with the generous support of the US Agency for International Development (USAID), the Ministry of Foreign Affairs of the Netherlands, and the Bill \& Melinda Gates Foundation; a full list of IAVI donors is available at www.iavi.org. Use of the 23-ID sector at Advanced Photon Source was supported by the US Department of Energy. The microbial glycan array was developed in part under funding from the Consortium for Functional Glycomics (NIH NIGMS GM062116 to JCP). The contents of this publication are solely the responsibility of the authors and do not necessarily represent the official views of the National Institute of General Medical Sciences, the National Institute of Allergy and Infectious Diseases, the NIH, USAID, or the US government. This is publication 29312 from The Scripps Research Institute.

Address correspondence to: Luc Teyton, The Scripps Research Institute, $10550 \mathrm{~N}$. Torrey Pines Road, IMM-23, La Jolla, California 92037, USA. Phone: 858.784.2552; E-mail: lteyton@scripps. edu. Or to: M.G. Finn, Georgia Institute of Technology, 950 Atlantic Drive, MoSE Room 2201B, Atlanta, Georgia 30332, USA. Phone: 404.385.0906; E-mail:mgfinn@gatech.edu.

MCA's present address is: Institute for Complex Molecular Systems, Eindhoven University of Technology, Eindhoven, Netherlands. 
1. Astronomo RD, Burton DR. Carbohydrate vaccines: developing sweet solutions to sticky situations? Nat Rev Drug Discov. 2010;9(4):308-324.

2. Trotter CL, et al. Optimising the use of conjugate vaccines to prevent disease caused by Haemophilus influenzae type b, Neisseria meningitidis and Streptococcus pneumoniae. Vaccine. 2008;26(35):4434-4445.

3. Durando P, Faust SN, Fletcher M, Krizova P, Torres A, Welte T. Experience with pneumococcal polysaccharide conjugate vaccine (conjugated to CRM197 carrier protein) in children and adults. Clin Microbiol Infect. 2013;19(suppl 1):1-9.

4. Bonten MJ, et al. Polysaccharide conjugate vaccine against pneumococcal pneumonia in adults. N Engl JMed. 2015;372(12):1114-1125.

5. Weintraub A. Immunology of bacterial polysaccharide antigens. Carbohydr Res. 2003;338(23):2539-2547.

6. Mond JJ, Lees A, Snapper CM. T cellindependent antigens type 2. Annu Rev Immunol. 1995;13:655-692.

7. Beuvery EC, van Rossum F, Nagel J. Comparison of the induction of immunoglobulin $\mathrm{M}$ and $\mathrm{G}$ antibodies in mice with purified pneumococcal type 3 and meningococcal group C polysaccharides and their protein conjugates. Infect Immun. 1982;37(1):15-22.

8. Mitchison NA. The carrier effect in the secondary response to hapten-protein conjugates. II. Cellular cooperation. Eur JImmunol. 1971;1(1):18-27.

9. Amanna IJ, Carlson NE, Slifka MK. Duration of humoral immunity to common viral and vaccine antigens. N Engl J Med. 2007;357(19):1903-1915.

10. Lee YC, et al. Haemophilus influenzae type b vaccine failure in children is associated with inadequate production of high-quality antibody. Clin Infect Dis. 2008;46(2):186-192.

11. Ekström N, et al. Kinetics and avidity of antibodies evoked by heptavalent pneumococcal conjugate vaccines PncCRM and PncOMPC in the Finnish Otitis Media Vaccine Trial. Infect Immun. 2005;73(1):369-377.

12. Usinger WR, Lucas AH. Avidity as a determinant of the protective efficacy of human antibodies to pneumococcal capsular polysaccharides. Infect Immun. 1999;67(5):2366-2370.

13. Cygler M, Rose DR, Bundle DR. Recognition of a cell-surface oligosaccharide of pathogenic Salmonella by an antibody Fab fragment. Science. 1991;253(5018):442-445.

14. Villeneuve $\mathrm{S}$, et al. Crystal structure of an anti-carbohydrate antibody directed against Vibrio cholerae O1 in complex with antigen: molecular basis for serotype specificity. Proc Natl Acad Sci U S A. 2000;97(15):8433-8438.

15. Vyas NK, et al. Molecular recognition of oligosaccharide epitopes by a monoclonal Fab specific for Shigella flexneri Y lipopolysaccharide: X-ray structures and thermodynamics. Biochemistry. 2002;41(46):13575-13586.

16. Harris SL, Fernsten P. Thermodynamics and density of binding of a panel of antibodies to high-molecular-weight capsular polysaccharides. Clin Vaccine Immunol. 2009;16(1):37-42.

17. Oberli MA, et al. Molecular analysis of carbohydrate-antibody interactions: case study using a Bacillus anthracis tetrasaccharide. JAm
Chem Soc. 2010;132(30):10239-10241.

18. Theillet FX, et al. Dynamic aspects of antibody:oligosaccharide complexes characterized by molecular dynamics simulations and saturation transfer difference nuclear magnetic resonance. Glycobiology. 2011;21(12):1570-1579.

19. Haji-Ghassemi O, Blackler RJ, Young NM, Evans SV. Antibody recognition of carbohydrate epitopes. Glycobiology. 2015;25(9):920-952.

20. Bai L, et al. Natural killer T (NKT)-B-cell interactions promote prolonged antibody responses and long-term memory to pneumococcal capsular polysaccharides. Proc Natl Acad Sci U S A. 2013;110(40):16097-16102.

21. Ishioka GY, et al. MHC interaction and T cell recognition of carbohydrates and glycopeptides. J Immunol. 1992;148(8):2446-2451.

22. Deck B, Elofsson M, Kihlberg J, Unanue ER. Specificity of glycopeptide-specific T cells. J Immunol. 1995;155(3):1074-1078.

23. Harding CV, Kihlberg J, Elofsson M, Magnusson G, Unanue ER. Glycopeptides bind MHC molecules and elicit specific $\mathrm{T}$ cell responses. J Immunol. 1993;151(5):2419-2425.

24. Pellicci DG, et al. Recognition of $\beta$-linked self glycolipids mediated by natural killer T cell antigen receptors. Nat Immunol. 2011;12(9):827-833.

25. Deck MB, Sjölin P, Unanue ER, Kihlberg J. MHC-restricted, glycopeptide-specific T cells show specificity for both carbohydrate and peptide residues. J Immunol.1999;162(8):4740-4744.

26. Mogemark M, Cirrito TP, Sjölin P, Unanue ER, Kihlberg J. Influence of saccharide size on the cellular immune response to glycopeptides. Org Biomol Chem. 2003;1(12):2063-2069.

27. Kabat EA. The upper limit for the size of the human antidextran combining site. JImmunol. 1960;84:82-85.

28. Verez-Bencomo V, et al. A synthetic conjugate polysaccharide vaccine against Haemophilus influenzae type b. Science. 2004;305(5683):522-525.

29. Adamo R, Nilo A, Castagner B, Boutureira O, Berti F, Bernardes GJ. Synthetically defined glycoprotein vaccines: current status and future directions. Chem Sci. 2013;4(8):2995-3008.

30. Bendelac A, Savage PB, Teyton L. The biology of NKT cells. Annu Rev Immunol. 2007;25:297-336.

31. Liu Y, et al. A modified $\alpha$-galactosyl ceramide for staining and stimulating natural killer $\mathrm{T}$ cells. Jimmunol Methods. 2006;312(1-2):34-39.

32. Carnaud C, et al. Cutting edge: cross-talk between cells of the innate immune system: NKT cells rapidly activate NK cells. J Immunol. 1999;163(9):4647-4650.

33. Hermans IF, et al. Dendritic cell function can be modulated through cooperative actions of TLR ligands and invariant NKT cells. J Immunol. 2007;178(5):2721-2729.

34. Galli G, et al. Invariant NKT cells sustain specific B cell responses and memory. Proc Natl Acad Sci U S A. 2007;104(10):3984-3989.

35. Andrews NJ, et al. Serotype-specific effectiveness and correlates of protection for the 13-valent pneumococcal conjugate vaccine: a postlicensure indirect cohort study. Lancet Infect Dis. 2014;14(9):839-846.

36. Fattom A, Matalon A, Buerkert J, Taylor K, Damaso S, Boutriau D. Efficacy profile of a bivalent Staphy- lococcus aureus glycoconjugated vaccine in adults on hemodialysis: phase III randomized study. Hum Vaccin Immunother. 2015;11(3):632-641.

37. Romero-Steiner S, Frasch CE, Carlone G, Fleck RA, Goldblatt D, Nahm MH. Use of opsonophagocytosis for serological evaluation of pneumococcal vaccines. Clin Vaccine Immunol. 2006;13(2):165-169.

38. Stowell SR, et al. Microbial glycan microarrays define key features of host-microbial interactions. Nat Chem Biol. 2014;10(6):470-476

39. Esposito S, et al. Safety and immunogenicity of a 13-valent pneumococcal conjugate vaccine compared to those of a 7-valent pneumococcal conjugate vaccine given as a three-dose series with routine vaccines in healthy infants and toddlers. Clin Vaccine Immunol. 2010;17(6):1017-1026.

40. Bentley SD, et al. Genetic analysis of the capsular biosynthetic locus from all 90 pneumococcal serotypes. PLoS Genet. 2006;2(3):e31.

41. Safari D, et al. Identification of the smallest structure capable of evoking opsonophagocytic antibodies against Streptococcus pneumoniae type 14. Infect Immun. 2008;76(10):4615-4623.

42. Benaissa-Trouw B, Lefeber DJ, Kamerling JP, Vliegenthart JF, Kraaijeveld K, Snippe H. Synthetic polysaccharide type 3-related di-, tri-, and tetrasaccharide-CRM(197) conjugates induce protection against Streptococcus pneumoniae type 3 in mice. Infect Immun. 2001;69(7):4698-4701.

43. Hong V, Presolski SI, Ma C, Finn MG. Analysis and optimization of copper-catalyzed azidealkyne cycloaddition for bioconjugation. Angew Chem Int Ed Engl. 2009;48(52):9879-9883.

44. Low JG, et al. Safety and immunogenicity of a virus-like particle pandemic influenza A (H1N1) 2009 vaccine: results from a double-blinded, randomized Phase I clinical trial in healthy Asian volunteers. Vaccine. 2014;32(39):5041-5048.

45. Yin Z, et al. Boosting immunity to small tumor-associated carbohydrates with bacteriophage $\mathrm{q} \beta$ capsids. ACS Chem Biol. 2013;8(6):1253-1262.

46. Briles DE, Crain MJ, Gray BM, Forman C, Yother J. Strong association between capsular type and virulence for mice among human isolates of Streptococcus pneumoniae. Infect Immun 1992;60(1):111-116.

47. McHeyzer-Williams M, Okitsu S, Wang N, McHeyzer-Williams L. Molecular programming of B cell memory. Nat Rev Immunol. 2011;12(1):24-34.

48. Colino J, Shen Y, Snapper CM. Dendritic cells pulsed with intact Streptococcus pneumoniae elicit both protein- and polysaccharidespecific immunoglobulin isotype responses in vivo through distinct mechanisms. J Exp Med. 2002;195(1):1-13

49. Giudicelli V, et al. IMGT/LIGM-DB, the IMGT comprehensive database of immunoglobulin and $\mathrm{T}$ cell receptor nucleotide sequences. Nucleic Acids Res. 2006;34(Database issue):D781-D784.

50. Scherer EM, Zwick MB, Teyton L, Burton DR. Difficulties in eliciting broadly neutralizing antiHIV antibodies are not explained by cardiolipin autoreactivity. AIDS. 2007;21(16):2131-2139.

51. Alam SM, et al. Role of HIV membrane in neutralization by two broadly neutralizing antibodies. Proc Natl Acad Sci U S A. 2009;106(48):20234-20239. 
52. van der Woude MW, Bäumler AJ. Phase and antigenic variation in bacteria. Clin Microbiol Rev. 2004;17(3):581-611.

53. Connolly ML. Solvent-accessible surfaces of proteins and nucleic acids. Science. 1983;221(4612):709-713.

54. Jegerlehner A, Maurer P, Bessa J, Hinton HJ, Kopf $\mathrm{M}$, Bachmann MF. TLR9 signaling in B cells determines class switch recombination to IgG2a. J Immunol. 2007;178(4):2415-2420.

55. Breitfeld D, et al. Follicular B helper T cells express CXC chemokine receptor 5, localize to $\mathrm{B}$ cell follicles, and support immunoglobulin production. J Exp Med. 2000;192(11):1545-1552.

56. Crotty S. T follicular helper cell differentiation, function, and roles in disease. Immunity. 2014;41(4):529-542.

57. Avci FY, Li X, Tsuji M, Kasper DL. A mechanism for glycoconjugate vaccine activation of the adaptive immune system and its implications for vaccine design. Nat Med.2011;17(12):1602-1609.

58. Day CL, et al. Ex vivo analysis of human memory CD4 $\mathrm{T}$ cells specific for hepatitis $\mathrm{C}$ virus using MHC class II tetramers. J Clin Invest. 2003;112(6):831-842.

59. Landais E, et al. New design of MHC class II tetramers to accommodate fundamental principles of antigen presentation. JImmunol. 2009;183(12):7949-7957.

60. Iwasaki A, Medzhitov R. Regulation of adaptive immunity by the innate immune system. Science. 2010;327(5963):291-295.

61. Leadbetter EA, et al. NK T cells provide lipid antigen-specific cognate help for B cells. Proc Natl Acad Sci U S A. 2008;105(24):8339-8344.

62. Chang PP, et al. Identification of Bcl-6dependent follicular helper NKT cells that provide cognate help for B cell responses. Nat Immunol. 2011;13(1):35-43.

63. Hua Z, Hou B. TLR signaling in B-cell development and activation. Cell Mol Immunol.
2013;10(2):103-106.

64. Kasturi SP, et al. Programming the magnitude and persistence of antibody responses with innate immunity. Nature. 2011;470(7335):543-547.

65. Jennings GT, Bachmann MF. The coming of age of virus-like particle vaccines. Biol Chem. 2008;389(5):521-536.

66. Cavallari M, et al. A semisynthetic carbohydrate-lipid vaccine that protects against $S$. pneumoniae in mice. Nat Chem Biol. 2014;10(11):950-956.

67. Broecker F, et al. Synthetic lipoteichoic acid glycans are potential vaccine candidates to protect from clostridium difficile infections. Cell Chem Biol. 2016;23(8):1014-1022.

68. Wedemayer GJ, Patten PA, Wang LH, Schultz PG, Stevens RC. Structural insights into the evolution of an antibody combining site. Science. 1997;276(5319):1665-1669.

69. Baxendale HE, Davis Z, White HN, Spellerberg $\mathrm{MB}$, Stevenson FK, Goldblatt D. Immunogenetic analysis of the immune response to pneumococcal polysaccharide. Eur J Immunol. 2000;30(4):1214-1223.

70. Dal Porto JM, Haberman AM, Shlomchik MJ, Kelsoe G. Antigen drives very low affinity B cells to become plasmacytes and enter germinal centers. J Immunol. 1998;161(10):5373-5381.

71. $\mathrm{Wu} \mathrm{H}$, et al. Ultra-potent antibodies against respiratory syncytial virus: effects of binding kinetics and binding valence on viral neutralization. JMol Biol. 2005;350(1):126-144.

72. Maynard JA, et al. Protection against anthrax toxin by recombinant antibody fragments correlates with antigen affinity. Nat Biotechnol. 2002;20(6):597-601.

73. Ekström N, Väkeväinen M, Verho J, Kilpi T, Käyhty H. Functional antibodies elicited by two heptavalent pneumococcal conjugate vaccines in the Finnish Otitis Media Vaccine Trial. Infect Immun. 2007;75(4):1794-1800.

74. Tian H, Weber S, Thorkildson P, Kozel TR,
Pirofski LA. Efficacy of opsonic and nonopsonic serotype 3 pneumococcal capsular polysaccharide-specific monoclonal antibodies against intranasal challenge with Streptococcus pneumoniae in mice. Infect Immun. 2009;77(4):1502-1513.

75. Ramsland PA, Farrugia W, Bradford TM, Mark Hogarth P, Scott AM. Structural convergence of antibody binding of carbohydrate determinants in Lewis Y tumor antigens. J Mol Biol. 2004;340(4):809-818.

76. Nagae M, et al. Crystal structure of anti-polysialic acid antibody single chain $\mathrm{Fv}$ fragment complexed with octasialic acid: insight into the binding preference for polysialic acid. J Biol Chem. 2013;288(47):33784-33796.

77. Lemieux RU. How water provides the impetus for molecular recognition in aqueous solution. Acc Chem Res. 1996;29(8):373-380.

78. Adachi $\mathrm{O}$, et al. Targeted disruption of the MyD88 gene results in loss of IL-1- and IL-18mediated function. Immunity. 1998;9(1):143-150.

79. Yamamoto M, et al. Role of adaptor TRIF in the MyD88-independent toll-like receptor signaling pathway. Science. 2003;301(5633):640-643.

80. Madsen L, et al. Mice lacking all conventional MHC class II genes. Proc Natl Acad Sci U S A. 1999;96(18):10338-10343.

81. Berger M, Moresco EMY, Beutler BA. Mutagenetix Database. UT Southwestern Medical Center Web site. http://mutagenetix.utsouthwestern.edu/. Updated February 8, 2017. Accessed February 8, 2017.

82. Mallet-Designe VI, Stratmann T, Homann D, Carbone F, Oldstone MB, Teyton L. Detection of low-avidity CD4+ T cells using recombinant artificial APC: following the antiovalbumin immune response. JImmunol. 2003;170(1):123-131.

83. Lefranc MP, et al. IMGT unique numbering for immunoglobulin and $\mathrm{T}$ cell receptor variable domains and Ig superfamily V-like domains. Dev Comp Immunol. 2003;27(1):55-77. 